\title{
The exponential eigenmodes of the carbon-climate system, and their implications for ratios of responses to forcings
}

\author{
M. R. Raupach \\ CSIRO Marine and Atmospheric Research, Canberra, ACT 2601, Australia \\ Correspondence to: M. R. Raupach (michael.raupach@csiro.au) \\ Received: 30 July 2012 - Published in Earth Syst. Dynam. Discuss.: 19 September 2012 \\ Revised: 30 November 2012 - Accepted: 22 December 2012 - Published: 25 January 2013
}

\begin{abstract}
Several basic ratios of responses to forcings in the carbon-climate system are observed to be relatively steady. Examples include the $\mathrm{CO}_{2}$ airborne fraction (the fraction of the total anthropogenic $\mathrm{CO}_{2}$ emission flux that accumulates in the atmosphere) and the ratio $T / Q_{\mathrm{E}}$ of warming $(T)$ to cumulative total $\mathrm{CO}_{2}$ emissions $\left(Q_{\mathrm{E}}\right)$. This paper explores the reason for such near-constancy in the past, and its likely limitations in future.

The contemporary carbon-climate system is often approximated as a set of first-order linear systems, for example in response-function descriptions. All such linear systems have exponential eigenfunctions in time (an eigenfunction being one that, if applied to the system as a forcing, produces a response of the same shape). This implies that, if the carbonclimate system is idealised as a linear system (Lin) forced by exponentially growing $\mathrm{CO}_{2}$ emissions (Exp), then all ratios of responses to forcings are constant. Important cases are the $\mathrm{CO}_{2}$ airborne fraction (AF), the cumulative airborne fraction $(\mathrm{CAF})$, other $\mathrm{CO}_{2}$ partition fractions and cumulative partition fractions into land and ocean stores, the $\mathrm{CO}_{2}$ sink uptake rate $\left(k_{\mathrm{S}}\right.$, the combined land and ocean $\mathrm{CO}_{2}$ sink flux per unit excess atmospheric $\mathrm{CO}_{2}$ ), and the ratio $T / Q_{\mathrm{E}}$. Further, the $\mathrm{AF}$ and the $\mathrm{CAF}$ are equal. Since the Lin and Exp idealisations apply approximately to the carbon-climate system over the past two centuries, the theory explains the observed near-constancy of the $\mathrm{AF}, \mathrm{CAF}$ and $T / Q_{\mathrm{E}}$ in this period.

A nonlinear carbon-climate model is used to explore how future breakdown of both the Lin and Exp idealisations will cause the $\mathrm{AF}, \mathrm{CAF}$ and $k_{\mathrm{S}}$ to depart significantly from constancy, in ways that depend on $\mathrm{CO}_{2}$ emissions scenarios. However, $T / Q_{\mathrm{E}}$ remains approximately constant in typical scenarios, because of compensating interactions between $\mathrm{CO}_{2}$ emissions trajectories, carbon-climate nonlinearities (in
\end{abstract}

land-air and ocean-air carbon exchanges and $\mathrm{CO}_{2}$ radiative forcing), and emissions trajectories for non- $\mathrm{CO}_{2}$ gases. This theory establishes a basis for the widely assumed proportionality between $T$ and $Q_{\mathrm{E}}$, and identifies the limits of this relationship.

\section{Introduction}

The global carbon-climate system has a number of stable properties, despite massive anthropogenic perturbation since the onset of industrialisation in the 18th century. The $\mathrm{CO}_{2}$ airborne fraction (the fraction of the total anthropogenic $\mathrm{CO}_{2}$ emission flux that accumulates in the atmosphere) has stayed close to a mean of about 0.44 for the last $50 \mathrm{yr}$, despite significant interannual variability and a small observed trend (Le Quéré et al., 2009). The ratio $T / Q_{\mathrm{E}}$ of warming $(T)$ to cumulative total $\mathrm{CO}_{2}$ emissions $\left(Q_{\mathrm{E}}\right)$ is also close to steady, not only in the past but in many future projections (Allen et al., 2009; Meinshausen et al., 2009; Matthews et al., 2009; Raupach et al., 2011), at around $2 \mathrm{~K}$ per trillion tonnes of carbon.

This paper investigates the conditions under which ratios like the airborne fraction and $T / Q_{\mathrm{E}}$ are steady, and the limits of such behaviour. The approach is to identify some general analytic properties of linearised models of the carbon-climate system, and then to test the limits of this idealisation. This is done in three steps, tackled respectively in Sects. 2, 3 and 4. First, it is shown in Sect. 2 that a wide class of first-order linear systems has exponential eigenfunctions (functions that, when applied to the system as a forcing, produce a response of the same shape), and that for this class of systems, all ratios of responses to forcings are constant. Next, in Sect. 3, 
this basic theorem is applied to the carbon-climate system under a "LinExp" idealisation, in which the system is linear or linearised (Lin) and is forced with exponentially growing anthropogenic $\mathrm{CO}_{2}$ emissions (Exp). In this idealisation, constant ratios include the $\mathrm{CO}_{2}$ airborne fraction, its cumulative counterpart, other $\mathrm{CO}_{2}$ partition fractions, the $\mathrm{CO}_{2}$ sink uptake rate, and the ratio $T / Q_{\mathrm{E}}$. These predictions are tested directly against observations. Finally, in Sect. 4, the predictions of the LinExp idealisation are compared with predictions from a nonlinear model of the carbon-climate system, to investigate the applicability of the LinExp idealisation to future projections. Mathematical and modelling details are given in Appendices A and B, respectively.

The restricted LinExp world is not as great a distortion of current reality as might at first appear. Assumption Exp is historically approximately true for total $\mathrm{CO}_{2}$ emissions from fossil fuel combustion and net deforestation from 1750 to 2010 (Jarvis et al., 2012, and Fig. 1 below), and $\mathrm{CO}_{2}$ is the dominant net anthropogenic radiative forcing because of past near-cancellation of anthropogenic forcings from non$\mathrm{CO}_{2}$ gases and from non-gaseous influences, mainly aerosols (IPCC, 2007). Assumption Lin is widely used in the form of response-function models for parts of the global carbon cycle (for example, Joos et al., 1996; Trudinger et al., 2002; Enting, 2007; Li et al., 2009), and for the response of the global climate system to specified radiative forcing (for example, Huntingford and Cox, 2000; Hansen et al., 2008; Li and Jarvis, 2009). There are nonlinearities in the coupling between these linear model components, especially through the dependence of $\mathrm{CO}_{2}$ radiative forcing and the ocean-air and land-air carbon exchanges on $\mathrm{CO}_{2}$ concentration. These are incorporated in many models of the coupled carbon-climate system through weakly nonlinear coupling between otherwise linear model components (Hasselmann et al., 1997; Petschel-Held et al., 1999; Hooss et al., 2001; Joos et al., 2001, 2012; Raper et al., 2001; also the nonlinear model used here). Fully linear versions of such models can always be developed within a limited subspace around any given state of the Earth system, because a weakly nonlinear carbon-climate model can be linearised about that state. For these reasons, the LinExp idealisation turns out to be a useful approximate description of many aspects of the carbon-climate system from the 18th to the early 21 st century. However, both the Lin and Exp assumptions will almost certainly break down in the future, with consequences to be investigated in Sect. 4.

The mathematical analysis in this paper was presaged many years ago by Bacastow and Keeling (1979), who showed that the $\mathrm{CO}_{2}$ airborne fraction and related flux partition ratios are constant in the LinExp idealisation. Here, this is extended to all ratios between fluxes and state variables in the coupled carbon-climate system, and the limits of the idealisation are explored.

\section{Theory}

\subsection{General and linearised carbon-climate models}

A model for the carbon-climate system can be regarded as a set of nonlinear equations

$\mathrm{d} \boldsymbol{x} / \mathrm{d} t=\boldsymbol{f}(t)+\boldsymbol{\Phi}(\boldsymbol{x})$,

where $\boldsymbol{x}(t)$ is a carbon-climate state vector of matter and energy stores (here taken to be perturbations about a preindustrial equilibrium state $\boldsymbol{x}=0), \boldsymbol{f}(t)$ a vector of anthropogenic forcing fluxes, $\boldsymbol{\Phi}(\boldsymbol{x})$ a vector of system response fluxes, and $t$ time. The forcing flux vector $\boldsymbol{f}(t)$ is externally prescribed. The response flux vector $\boldsymbol{\Phi}(\boldsymbol{x})$, the net fluxes into different stores $(\boldsymbol{x})$ arising from the response of the system to forcing, is specified by nonlinear "phenomenological equations" embodying model parameterisations.

Equation (1) is a general representation of a carbonclimate model of any sophistication. The dimension of the state vector $\boldsymbol{x}(t)$ may be of order 10 for a simple, globally aggregated model, or $10^{7}$ for a sophisticated, spatially resolved model.

The response flux vector $\boldsymbol{\Phi}(\boldsymbol{x})$ can be linearised as $-\mathbf{K} \boldsymbol{x}$, where $-\mathbf{K}$ is the system response matrix (see Appendix A1). Then, Eq. (1) becomes a linear system of first-order ordinary differential equations:

$\mathrm{d} \boldsymbol{x} / \mathrm{d} t=\boldsymbol{f}(t)-\mathbf{K} \boldsymbol{x}$ with $\boldsymbol{x}(0)=0$.

The solution of this linear system for state variables $\boldsymbol{x}(t)$ is

$\boldsymbol{x}(t)=\int_{0}^{t} \mathbf{G}(t-\tau) \boldsymbol{f}(\tau) \mathrm{d} \tau$,

where $\mathbf{G}(t)$ is the matrix pulse response function (PRF), Green's function or impulse response function for the system; see references in the Introduction for carbon-climate applications. The element $G_{i j}(t)$ of $\mathbf{G}(t)$ is the fraction of a pulse input at time $t=0$ into store $j$ that appears at time $t$ in store $i$. Formally, the PRF is given by $\mathbf{G}(t)=\exp (-\mathbf{K} t)$, where exp denotes the matrix exponential (Glendinning, 1994); a more practical expression for $\mathbf{G}(t)$ is given below.

\subsection{Normal modes}

In Eq. (2), the system response matrix $\mathbf{K}$ has off-diagonal terms representing coupling or feedback between different components of $\boldsymbol{x}$. A standard technique for treating coupled linear problems of this sort is the method of normal modes (Gershenfeld, 1999, p. 12; Enting, 2007). The principle (see Appendix A2 for detail) is to transform the state space into a reference frame in which $\mathbf{K}$ becomes a diagonal matrix $\Lambda$ and the state variables $\boldsymbol{x}(t)$ become new variables $\boldsymbol{y}(t)$, the "normal modes". In the new reference frame, Eq. (2) becomes:

$\mathrm{d} \boldsymbol{y} / \mathrm{d} t=\mathbf{U}^{-1} \boldsymbol{f}(t)-\Lambda \boldsymbol{y}$ with $\boldsymbol{y}(0)=0$, 
where $\mathbf{U}$ is the matrix of column eigenvectors of $\mathbf{K}$, and $\Lambda$ is the diagonal matrix of its eigenvalues, $\lambda^{(m)}$ (see Appendix A2). Because $\Lambda$ is diagonal, this is a set of independent scalar equations that can be solved one by one. When the solution $\boldsymbol{y}(t)$ of Eq. (4) is transformed back to the original reference frame to yield $\boldsymbol{x}(t)$, the result is Eq. (3), with the elements $G_{i j}(t)$ of the PRF explicitly identified as weighted sums of decaying exponential terms:

$G_{i j}(t)=\sum_{m} a_{i j}^{(m)} \exp \left(-\lambda^{(m)} t\right)$

The decay rates are the eigenvalues $\lambda^{(m)}$ of $\mathbf{K}$, and the weights $a_{i j}^{(m)}$ are specified by the eigenvectors of $\mathbf{K}$ (see Eqs. A15 and A16).

It is assumed henceforth that the exponentials in $G_{i j}(t)$ decay in time (pending later verification in Sect. 4.1). This occurs when all eigenvalues $\lambda^{(m)}$ of $\mathbf{K}$ have positive real parts, so that the system defined by Eq. (2) is dynamically stable.

\subsection{Eigenmodes}

A linear system can be construed as a differential linear operator $L$ acting on an input $\boldsymbol{x}(t)$ to produce an output $L(\boldsymbol{x}(t))$. For the linear system of Eq. (2), the linear operator is

$L(\boldsymbol{x}(t))=\left(\frac{\mathrm{d}}{\mathrm{d} t}+\mathbf{K}\right) \boldsymbol{x}(t)$

so that Eq. (2) becomes $L(\boldsymbol{x}(t))=\boldsymbol{f}(t)$.

An important attribute of any linear operator $L$ is its set of eigenfunctions $\boldsymbol{v}(t)$, the functions for which the output is proportional to the input, so that $L(\boldsymbol{v}(t))=\alpha \boldsymbol{v}(t)$. The proportionality coefficient $\alpha$ is the eigenvalue corresponding to the eigenfunction $\boldsymbol{v}(t)$. An eigenmode is described by both $\alpha$ and $\boldsymbol{v}(t)$. If a linear system is forced with an eigenfunction, so that $\boldsymbol{f}(t)$ is proportional to $\boldsymbol{v}(t)$, then its response is the same eigenfunction.

For a first-order linear system, the eigenfunctions are exponentials in time (see Appendix A3 for a demonstration of this key fact). Therefore, an exponential forcing produces an exponential response with the same growth rate, so that ratios of responses to forcings are constant. For any other forcing, response/forcing ratios are not constant.

\subsection{Ratios among fluxes and state variables}

Tha above general result (that first-order linear systems have exponential eigenfunctions, so that response/forcing ratios are constant under exponential forcing) implies the following for LinExp systems: (a) all state variables grow at forcing rates, not response rates; (b) all ratios among state variables approach constant values; (c) all partition fractions (ratios of growth rates of state variables to the forcing flux) approach constant values; and (d) all ratios become independent of initial conditions faster than forcing rates. Sketch proofs are given in Appendix A4, using theory similar to Bacastow and Keeling (1979, their Appendix B).

These properties can be illustrated for one-dimensional systems obeying the scalar counterpart of Eq. (2), $x^{\prime}(t)=f(t)-k x$ (where the prime denotes a time derivative, $\left.x^{\prime}(t)=\mathrm{d} x / \mathrm{d} t\right)$. The scalar partition fraction is the ratio $x^{\prime}(t) / f(t)$, the fraction of the forcing that appears instantaneously as increase in the perturbation store $x(t)$. The cumulative partition fraction is $x(t) / Q(-\infty, t)$, the ratio of the response $x(t)$ to the cumulative forcing $Q(-\infty, t)$, where the cumulative forcing is the integral of $f(t)$ from time $-\infty$ to $t$. For a LinExp system, both fractions approach the same constant value (Appendix A4, Eq. A27):

$\frac{x^{\prime}(t)}{f(t)}=\frac{x(t)}{Q(t)}=\frac{r}{r+k}+$ transient

The transient term decays at the rate $r+k$. Since $r$ and $k$ are both positive for the systems under consideration, this is larger than both the forcing rate $(r)$ and the response rate $(k)$.

In the multi-dimensional case, the partition fractions are the fractions of the forcing flux entering the perturbation stores $x_{i}(t)$, and the cumulative partition fractions are the ratios of the stores themselves to cumulative forcing. When a LinExp system is forced exponentially with a growth rate $r_{1}$ in just the first component of the state vector $\boldsymbol{x}$, the partition fraction and cumulative partition fraction for store $i$ both approach the same value (Appendix A4, Eq. A29):

$\frac{x_{i}^{\prime}(t)}{f_{1}(t)}=\frac{x_{i}(t)}{Q_{1}(-\infty, t)}=\sum_{m} \frac{a_{i 1}^{(m)}}{r_{1}+\lambda^{(m)}}+$ transient,

where $Q_{1}(-\infty, t)$ is the cumulative forcing in the first component of $\boldsymbol{x}$. This is a weighted sum of the constant partition ratios $r_{1} /\left(r_{1}+\lambda^{(m)}\right)$ for different modes $m$ (compare with Eq. 7). The approach to this value occurs at a rate greater than $r_{1}$, for stable systems with $\lambda^{(m)}>0$.

The key implication of the above theory is that for a LinExp system, all ratios among fluxes and perturbation state variables approach constant values. This occurs because all linear systems of the class of Eq. (2) have exponential eigenfunctions, so that an exponential forcing function yields a response in which all state variables and response fluxes grow exponentially with the same growth rate as the forcing. Moreover, the system response locks onto constancy of ratios among fluxes and state variables at a rate determined by the forcing flux ( $r_{1}$ in Eq. 8), not the turnover rates for individual state variables (the elements of the system response matrix $\mathbf{K})$ or normal modes (the eigenvalues $\lambda^{(m)}$ of $\mathbf{K}$ ). This means that even for state variables with very slow turnover rates, constant partition fractions and cumulative partition fractions are reached relatively quickly when the forcing grows rapidly (Bacastow and Keeling, 1979). 


\section{Comparing linear theory with observations}

When the carbon-climate system is idealised as a LinExp system, constancy of ratios among fluxes and perturbation state variables implies that the following ratios are all constant: the $\mathrm{CO}_{2}$ airborne fraction, the cumulative airborne fraction, other $\mathrm{CO}_{2}$ partition and cumulative partition fractions into land and ocean stores, $\mathrm{CO}_{2}$ sink rates, and the ratio ( $\left.T / Q_{\mathrm{E}}\right)$ of warming $(T)$ to cumulative $\mathrm{CO}_{2}$ emissions $\left(Q_{\mathrm{E}}\right)$. These predictions can all be tested.

\section{1 $\mathrm{CO}_{2}$ airborne fraction, cumulative airborne fraction and sink rate}

The atmospheric $\mathrm{CO}_{2}$ mass balance is (Le Quéré et al., 2009):

$c_{\mathrm{A}}^{\prime}=f_{\mathrm{E}}+f_{\mathrm{L}}+f_{\mathrm{M}}$,

where $c_{\mathrm{A}}$ is the perturbation atmospheric $\mathrm{CO}_{2}$ store in $\mathrm{PgC}$ $\left(2.127\left(\left[\mathrm{CO}_{2}\right]-\left[\mathrm{CO}_{2}\right]_{q}\right)\right.$, with $\left[\mathrm{CO}_{2}\right]$ the $\mathrm{CO}_{2}$ mixing ratio in ppm and $\left[\mathrm{CO}_{2}\right]_{q}=280 \mathrm{ppm}=\left[\mathrm{CO}_{2}\right]$ at preindustrial equilibrium); $c_{\mathrm{A}}^{\prime}=\mathrm{d} c_{\mathrm{A}} / \mathrm{d} t$ is the atmospheric $\mathrm{CO}_{2}$ accumulation rate in $\mathrm{PgC}{ }^{-1} ; f_{\mathrm{E}}$ is the total $\mathrm{CO}_{2}$ emission flux $\left(f_{\mathrm{E}}=f_{\text {Foss }}+f_{\mathrm{LUC}}\right.$, including emissions from fossil fuels and other industry, $f_{\text {Foss }}$, and from net land use change, $\left.f_{\mathrm{LUC}}\right)$; and $f_{\mathrm{L}}$ and $f_{\mathrm{M}}$ are the $\mathrm{CO}_{2}$ land $(\mathrm{L})$ and ocean (M, marine) exchange fluxes. All fluxes have units $\mathrm{PgC} \mathrm{yr}^{-1}$ and are positive into the atmosphere. The cumulative $\mathrm{CO}_{2}$ mass balance is the integral of Eq. (9) from 1750 (a nominal preindustrial time) to $t$, denoting cumulative fluxes as $Q$ (in $\mathrm{PgC}$ ) and taking $c_{\mathrm{A}}=0$ at 1750 :

$c_{\mathrm{A}}=Q_{\mathrm{E}}+Q_{\mathrm{L}}+Q_{\mathrm{M}}, \quad Q_{\mathrm{E}}(t)=\int_{1750}^{t} f_{\mathrm{E}}(\tau) \mathrm{d} \tau$.

Fundamental carbon-cycle partition fractions are the airborne, land and ocean fractions (AF, LF and $\mathrm{OF}$ ), respectively, the fractions of the total $\mathrm{CO}_{2}$ emission flux remaining in the atmosphere and taken up by natural land and ocean $\mathrm{CO}_{2}$ sinks:

$\mathrm{AF}=\frac{c_{\mathrm{A}}^{\prime}}{f_{\mathrm{E}}}, \quad \mathrm{LF}=\frac{f_{\mathrm{L}}}{f_{\mathrm{E}}}, \quad \mathrm{OF}=\frac{f_{\mathrm{M}}}{f_{\mathrm{E}}}$.

Correspondingly, the cumulative airborne, land and ocean fractions (CAF, CLF and COF) are the fractions of cumulative $\mathrm{CO}_{2}$ emissions $\left(Q_{\mathrm{E}}\right)$ appearing in atmospheric, land and ocean stores:

$\mathrm{CAF}=\frac{c_{\mathrm{A}}}{Q_{\mathrm{E}}}, \quad \mathrm{CLF}=\frac{Q_{\mathrm{L}}}{Q_{\mathrm{E}}}, \quad \mathrm{COF}=\frac{Q_{\mathrm{M}}}{Q_{\mathrm{E}}}$.

Conservation of mass ensures that $\mathrm{AF}+\mathrm{LF}+\mathrm{OF}=1$ and $\mathrm{CAF}+\mathrm{CLF}+\mathrm{COF}=1$

If the carbon cycle obeys the LinExp idealisation, then the partition fractions and cumulative partition fractions are all constant in time and equal for each store, as shown by Eq. (8):

$\begin{aligned} \mathrm{AF} & =\mathrm{CAF}=\text { constant } \\ \mathrm{LF} & =\mathrm{CLF}=\text { constant } \\ \mathrm{OF} & =\mathrm{COF}=\text { constant. }\end{aligned}$

An observable quantity related to the $\mathrm{AF}$ is the $\mathrm{CO}_{2}$ sink rate $k_{\mathrm{S}}$, the strength of the combined land and ocean $\mathrm{CO}_{2}$ sink per unit excess $\mathrm{CO}_{2}$, with dimension 1/time:

$k_{\mathrm{S}}=\frac{-f_{\mathrm{L}}-f_{\mathrm{M}}}{c_{\mathrm{A}}}=\frac{f_{\mathrm{E}}-c_{\mathrm{A}}^{\prime}}{c_{\mathrm{A}}}$.

The latter equality follows from Eq. (9). The $\mathrm{AF}$ and $k_{\mathrm{S}}$ are related diagnostic quantities, because $k_{\mathrm{S}}=(1-\mathrm{AF}) f_{\mathrm{E}} / c_{\mathrm{A}}$, and both can be inferred from observations of $f_{\mathrm{E}}$ and $c_{\mathrm{A}}$.

The sink rate $k_{\mathrm{S}}$ has several properties: first, it is a measure of the "efficiency" of land and ocean $\mathrm{CO}_{2}$ sinks, in the sense of sink strength per unit excess $\mathrm{CO}_{2}$ (Gloor et al., 2010). Second, $k_{\mathrm{S}}$ can be readily split into separate contributions from land and ocean sinks, $k_{\mathrm{S}}=k_{\mathrm{L}}+k_{\mathrm{M}}$, with $k_{\mathrm{L}}=-f_{\mathrm{L}} / c_{\mathrm{A}}$ and $k_{\mathrm{M}}=-f_{\mathrm{M}} / c_{\mathrm{A}}$, to yield separate efficiency measures for land and ocean sinks. Third, $1 / k_{\mathrm{S}}$ is a natural time scale for land and ocean $\mathrm{CO}_{2}$ sinks, since $k_{\mathrm{S}}$ is the instantaneous fractional rate of decrease of excess $\mathrm{CO}_{2}$ due to sinks. Fourth, it can be shown (Appendix A5) that $k_{\mathrm{S}}$ is a time-dependent weighted mean of the turnover rates in the carbon cycle, with weights dependent on perturbation carbon stores.

For a LinExp carbon cycle, $k_{\mathrm{S}}, k_{\mathrm{L}}$ and $k_{\mathrm{M}}$ are all constant, because $f_{\mathrm{L}}, f_{\mathrm{M}}$ and $c_{\mathrm{A}}$ all increase exponentially at the same rate (the exponential forcing rate). However, $k_{\mathrm{S}}$ is far from constant with non-exponential emissions, as shown in the next section.

To compare the LinExp predictions for the AF, CAF and $k_{\mathrm{S}}$ with observations, it is first necessary to test whether $\mathrm{CO}_{2}$ emissions have grown exponentially. Figure 1 (upper panel) compares total $\mathrm{CO}_{2}$ emissions $f_{\mathrm{E}}(t)$ with an exponential trajectory from 1850 to 2011, using an average growth rate of $1.89 \% \mathrm{yr}^{-1}=(1 / 53) \mathrm{yr}^{-1}$ or a doubling time of $36.7 \mathrm{yr}$ (also see Jarvis et al., 2012). The short-term growth rate has oscillated around this average value, decreasing below it in the 1980s and 1990s and accelerating above it in the first decade of the 2000s (Le Quéré et al., 2009). Total cumulative $\mathrm{CO}_{2}$ emissions $Q_{\mathrm{E}}(t)$ have followed an exponential trajectory with the same growth rate remarkably closely since 1850 (Fig. 1, lower panel), apart from a small dip in the two decades before 1950 and a subsequent recovery in the two following decades. This indicates that departures of emissions $f_{\mathrm{E}}(t)$ from exponential behaviour have not been systematic.

Figure 2 shows the observed AF and CAF (from annual $\mathrm{CO}_{2}$ data) for 1850 to 2011, suggesting at first sight that the LinExp prediction $(\mathrm{AF}=\mathrm{CAF}=$ constant $)$ is quite a good approximation. Figure 3 demonstrates a near-proportional relationhip between perturbation atmospheric $\mathrm{CO}_{2}$ and cumulative total $\mathrm{CO}_{2}$ emissions, the slope of which is the CAF. From 

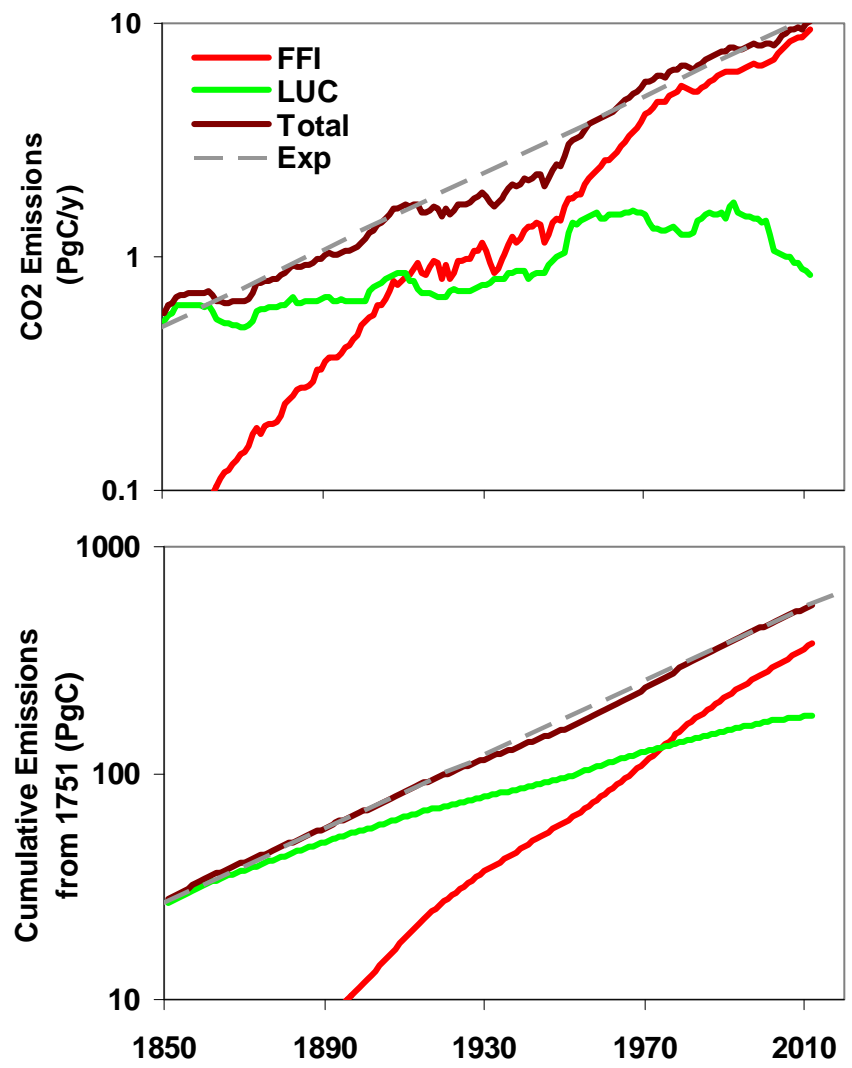

Fig. 1. Upper panel: observed total global $\mathrm{CO}_{2}$ emissions, $f_{\mathrm{E}}=f_{\text {Foss }}+f_{\mathrm{LUC}}$, as a function of time. Lower panel: cumulative global $\mathrm{CO}_{2}$ emissions, $Q_{\mathrm{E}}=Q_{\mathrm{Foss}}+Q_{\mathrm{LUC}}$. The vertical axis in both panels is logarithmic so that exponentially growing emissions would appear as a straight line. The dashed line in both panels indicates exponential growth, proportional to $e^{r t}$ with $r=1.89 \% \mathrm{yr}^{-1}$. Data sources: Appendix C.

1959 to 2011, the average AF was $0.44 \pm 0.15$ and the average CAF was $0.414 \pm 0.011$ ( $1 \sigma$ over annual values). Observational uncertainties are too large to infer the detailed behaviour of the AF or CAF prior to 1959, the start of in situ atmospheric $\mathrm{CO}_{2}$ measurements.

Although the LinExp idealisation is consistent with the observed near- constancy of the AF and CAF, further evidence suggests that departures from LinExp behaviour are observable in the carbon cycle. This evidence is of two kinds. First, recent papers (Canadell et al., 2007; Raupach et al., 2008; Le Quéré et al., 2009) have suggested that there is a detectable increasing trend in the AF from 1959 to the early $2000 \mathrm{~s}$, at a relative growth rate of 0.2 to $0.3 \% \mathrm{yr}^{-1}$. This finding has been contested on several grounds, mainly questioning the attribution of the observed trend in the $\mathrm{AF}$ rather than its existence: the observed trend has been attributed to slower-than-exponential growth in $f_{\mathrm{E}}$ (Gloor et al., 2010), to particular events such as volcanic eruptions and ENSO (El Niño-Southern Oscillation) events (Frölicher et al., 2012; Sarmiento et al., 2010), or to errors in $\mathrm{CO}_{2}$ emissions data in

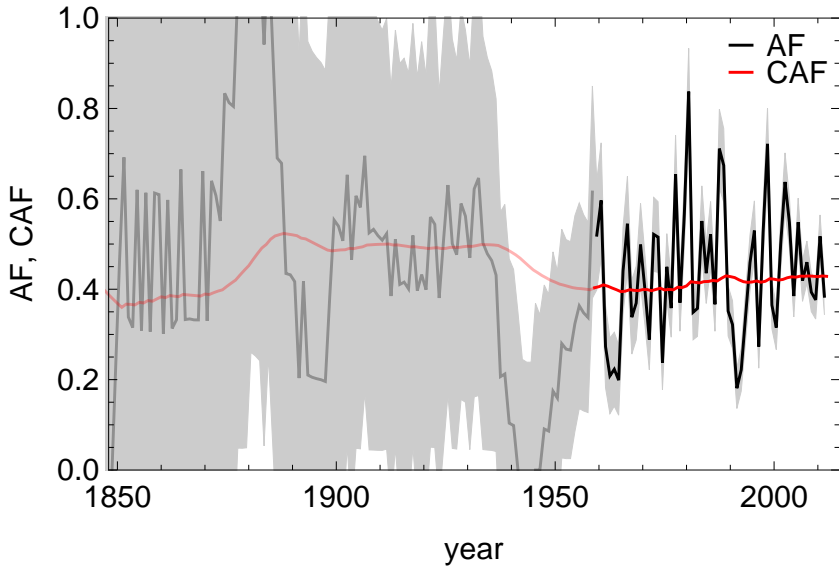

Fig. 2. Observed $\mathrm{CO}_{2}$ airborne fraction (AF, Eq. 11) and cumulative airborne fraction (CAF, Eq. 12). The grey band is an uncertainty estimate $( \pm 1 \sigma)$ for $\mathrm{AF}=c_{\mathrm{A}}^{\prime} / f_{\mathrm{E}}$, accounting for errors in both $\mathrm{CO}_{2}$ emissions $\left(f_{\mathrm{E}}=f_{\mathrm{Foss}}+f_{\mathrm{LUC}}\right)$ and atmospheric accumulation $\left(c_{\mathrm{A}}^{\prime}=\mathrm{d} c_{\mathrm{A}} / \mathrm{d} t\right.$, calculated from annual increments in $\left.c_{\mathrm{A}}\right)$. An uncertainty band for CAF is not shown here for clarity (it is shown elsewhere; see Figs. 7 and 9). Full and semi-transparent lines for both $\mathrm{AF}$ (black) and CAF (red) respectively denote the observations in the period of high-quality in situ atmospheric $\mathrm{CO}_{2}$ estimates (from 1959 onward) and the period before 1959 for which atmospheric $\mathrm{CO}_{2}$ is inferred from ice core data; the uncertainty is much larger before 1959. Data sources: Appendix C.

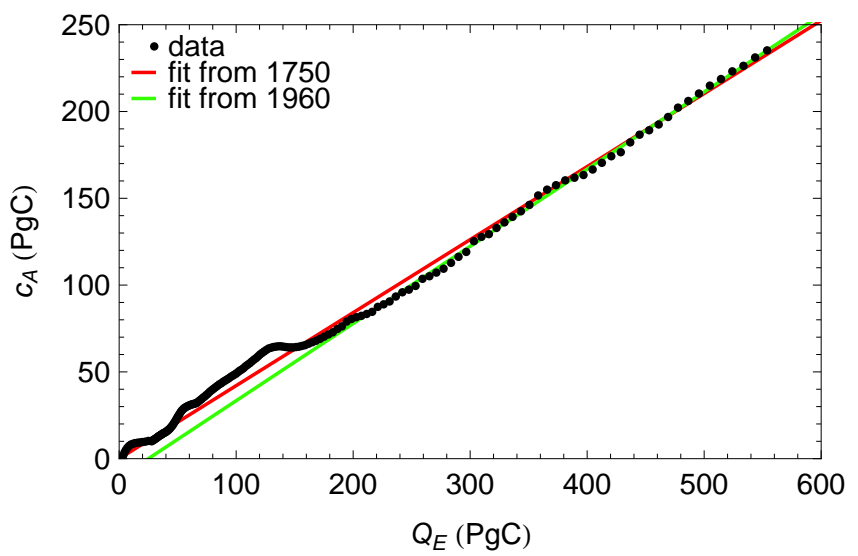

Fig. 3. Perturbation atmospheric $\mathrm{CO}_{2}$ store (in $\mathrm{PgC}$ ), $c_{\mathrm{A}}(t)$, as a function of cumulative total $\mathrm{CO}_{2}$ emissions, $Q_{\mathrm{E}}(t)$. Red line is a linear fit to data from 1750 to end of 2011, constrained to pass through the origin; green line is a linear fit to data from 1960 to end of 2011, not constrained to pass through the origin. Data sources: Appendix C.

the 1990s and early 2000s (Francey et al., 2010). Reconciliation of these different views on the attribution of observed $\mathrm{AF}$ trends is undertaken elsewhere.

Second, the LinExp prediction of constant $k_{\mathrm{S}}$ is tested in Fig. 4 by plotting direct observations of $k_{\mathrm{S}}$ from 1850 to 2011. From 1959 to $2011, k_{\mathrm{S}}$ declined significantly, by a 


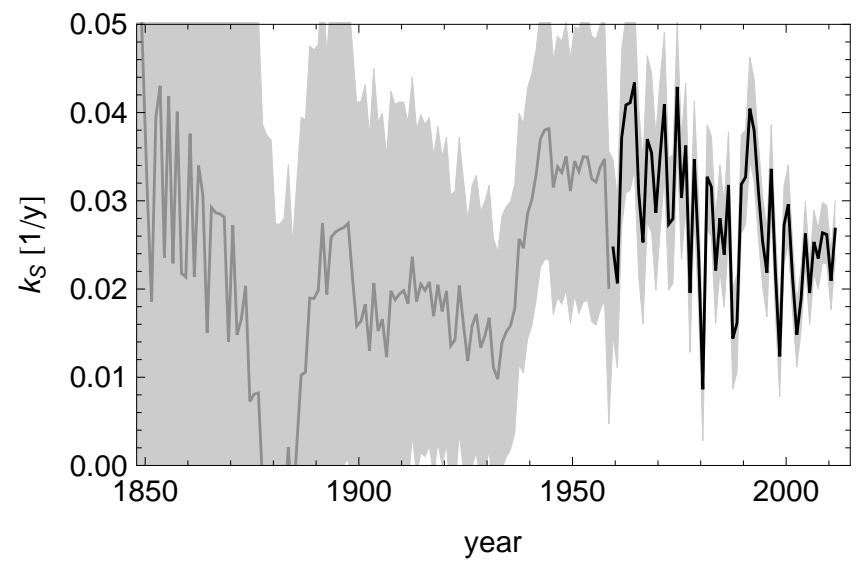

Fig. 4. Observed $\mathrm{CO}_{2}$ sink rate $k_{\mathrm{S}}$ (Eq. 14). As in Fig. 2, the grey band is an uncertainty estimate $( \pm 1 \sigma)$ accounting for errors in both $\mathrm{CO}_{2}$ emissions and $\mathrm{CO}_{2}$ concentration data, and full and semitransparent lines respectively denote observations in the period of high-quality in situ atmospheric $\mathrm{CO}_{2}$ estimates (from 1959 onward) and the period before 1959. Data sources: Appendix C.

factor of around 1/3. As with the AF, observational uncertainties prevent statements about trends before 1959. The observed behaviour of $k_{\mathrm{S}}$ is not in accord with the LinExp idealisation, or with the assumption (Gloor et al., 2010) that $k_{\mathrm{S}}$ is constant.

\subsection{Ratio of warming to cumulative emissions}

Several recent papers (Allen et al., 2009; Meinshausen et al., 2009; Matthews et al., 2009; Zickfeld et al., 2009) used numerical carbon-climate models to propose a near-linear relationship between global temperature perturbation $(T)$ and cumulative total $\mathrm{CO}_{2}$ emissions $\left(Q_{\mathrm{E}}\right)$ :

$T=\alpha Q_{\mathrm{E}}$.

The slope $\alpha$ is a form of transient climate sensitivity with units $\mathrm{KEgC}^{-1}\left(1 \mathrm{EgC}\right.$ or 1 exagram of carbon is $10^{18} \mathrm{gC}$ or 1 trillion tonnes of carbon). Matthews et al. (2009) have called $\alpha$ the "carbon-climate response". From Eq. (8), such a linear relationship holds under a LinExp idealisation of the coupled carbon-climate system, noting that this involves linearised descriptions of processes such as the dependence of radiative forcing on $\mathrm{CO}_{2}$ and other greenhouse gas concentrations (see Appendix B). The LinExp idealisation identifies conditions under which a proportional relationship between $T$ and $Q_{\mathrm{E}}$ can be expected, and also suggests that proportionality is likely to fail as either or both of the Lin and Exp assumptions break down.

Equation (15) is tested in Fig. 5 by plotting observed $T$ against $Q_{\mathrm{E}}$. The plot is noisier than Fig. 3 (observed $c_{\mathrm{A}}$ against $Q_{\mathrm{E}}$ ) but suggests that Eq. (15) is a useful approximation. The regression slope over the recent period (1959 to end of $2011 ; \alpha=2.13 \pm 0.13 \mathrm{~K} \mathrm{EgC}^{-1}$ ) is higher than over
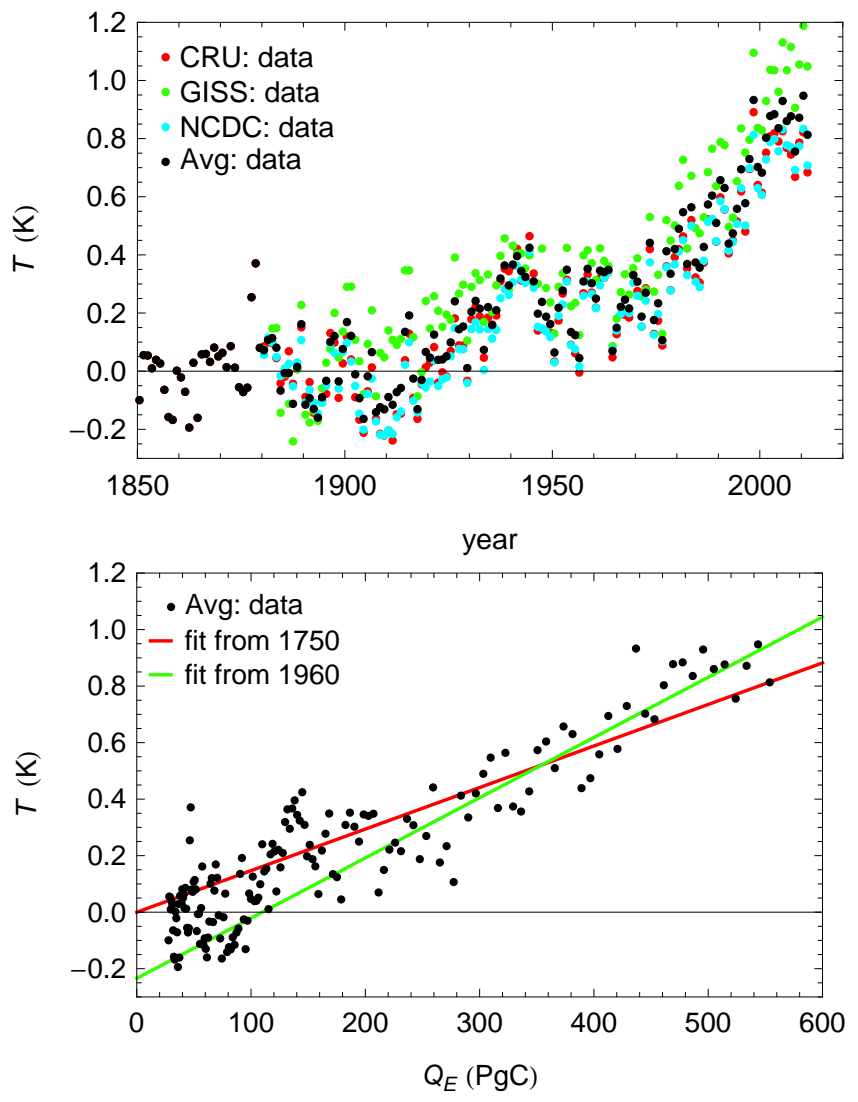

Fig. 5. Perturbation global temperature $T$ (referenced to 1880 1900) from three data sources, as a function of time $t$ (upper panel) and of cumulative $\mathrm{CO}_{2}$ emissions $Q_{\mathrm{E}}$ (lower panel). The average of all three series is shown as black points. In the lower panel, the red line is a linear fit to all available $T$ data (average over 3 sources) constrained to pass through the origin; green line is a linear fit to data from 1960 to 2011, not constrained to pass through the origin. Slopes are $\alpha=1.47 \mathrm{~K} \mathrm{EgC}^{-1}$ (red) and $2.13 \mathrm{~K} \mathrm{EgC}^{-1}$ (green). Data sources: Appendix C.

the whole record ( 1750 to $2011 ; \alpha=1.47 \pm 0.05 \mathrm{~K} \mathrm{EgC}^{-1}$ ). These values bracket the widely quoted slope in Eq. (15) of $\alpha \approx 2 \mathrm{~K} \mathrm{EgC}^{-1}$ (Allen et al., 2009).

\section{Future breakdown of the LinExp idealisation}

Figures 2 to 5 show that the LinExp idealisation applies approximately to the carbon-climate system from 1750 to the present, providing an explanation for the observed nearconstancy of the $\mathrm{AF}, \mathrm{CAF}$ and $T / Q_{\mathrm{E}}$. It is highly likely that the LinExp idealisation will break down in future, causing the $\mathrm{AF}, \mathrm{CAF}$ and the $\mathrm{CO}_{2}$ sink rate $k_{\mathrm{S}}$ to depart significantly from constancy. This can happen for one or more of three reasons: departures from linearity (failure of Lin), departures of emissions from exponential trajectories (failure of Exp), and the effects of radiative forcing agents other than $\mathrm{CO}_{2}$. Here, these effects are assessed by comparing predictions from the 

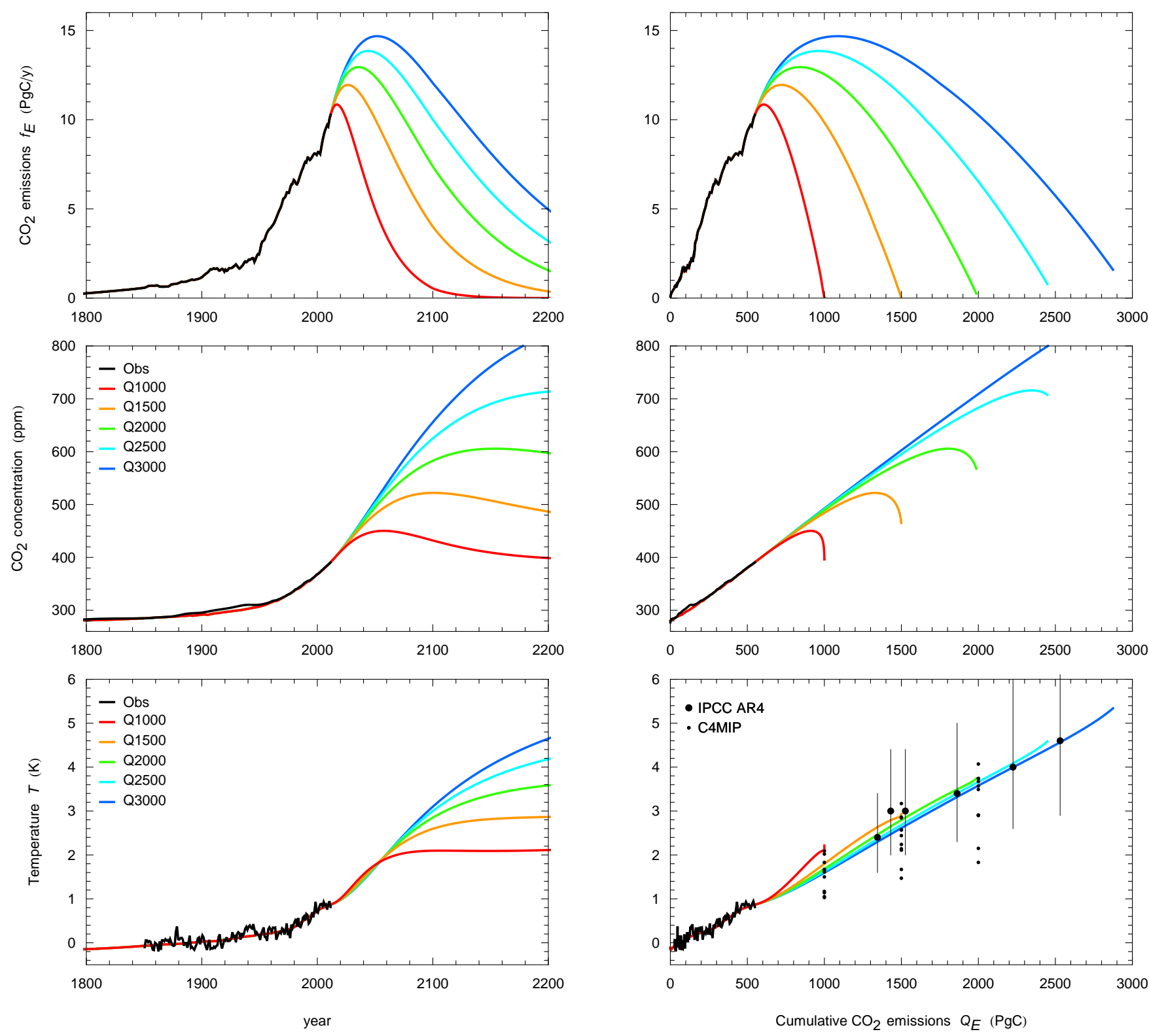

Fig. 6. Total $\mathrm{CO}_{2}$ emissions $\left(f_{\mathrm{E}}\right)$ and predictions for $\mathrm{CO}_{2}$ concentration and temperature $T$, with analytic emission scenarios for $\mathrm{CO}_{2}$ and non- $\mathrm{CO}_{2}$ gases yielding cumulative total $\mathrm{CO}_{2}$ emissions $Q_{\mathrm{E}}(\infty)$ from 1000 to $3000 \mathrm{PgC}$ (details in Appendix B). Left and right panels show plots against time and $Q_{\mathrm{E}}(t)$, respectively. In lower right panel, large points are IPCC AR4 projections (IPCC, 2007) for $T\left(Q_{\mathrm{E}}\right)$ in 2100 for SRES marker scenarios (from left) B1, A1T, B2, A1B, A2, A1FI, with 17-83\% uncertainties; small points are C4MIP projections (Matthews et al., 2009). Data sources: Appendix C.

LinExp idealisation with those from a nonlinear model of the carbon-climate system.

\subsection{Nonlinear model}

The nonlinear model is the Simple Carbon-Climate Model (SCCM) (Raupach et al., 2011; Harman et al., 2011). The form used here is briefly described Appendix B. SCCM is a globally aggregated model of the carbon-climate system, an approach with long antecedents (for example, Oeschger et al., 1975; also other references for response-function models given in the Introduction). Model state variables are carbon masses in the atmosphere, fast and slow land $\mathrm{C}$ stores and a set of ocean $\mathrm{C}$ stores; the atmospheric concentrations of $\mathrm{CH}_{4}, \mathrm{~N}_{2} \mathrm{O}$ and CFCs; and global perturbation temperature components. Radiative forcing of climate occurs from $\mathrm{CO}_{2}$, $\mathrm{CH}_{4}, \mathrm{~N}_{2} \mathrm{O}$, CFCs and aerosols. The model includes nonlinearities of several kinds: the response of terrestrial carbon assimilation to $\mathrm{CO}_{2}$, ocean carbonate chemistry, temperature 

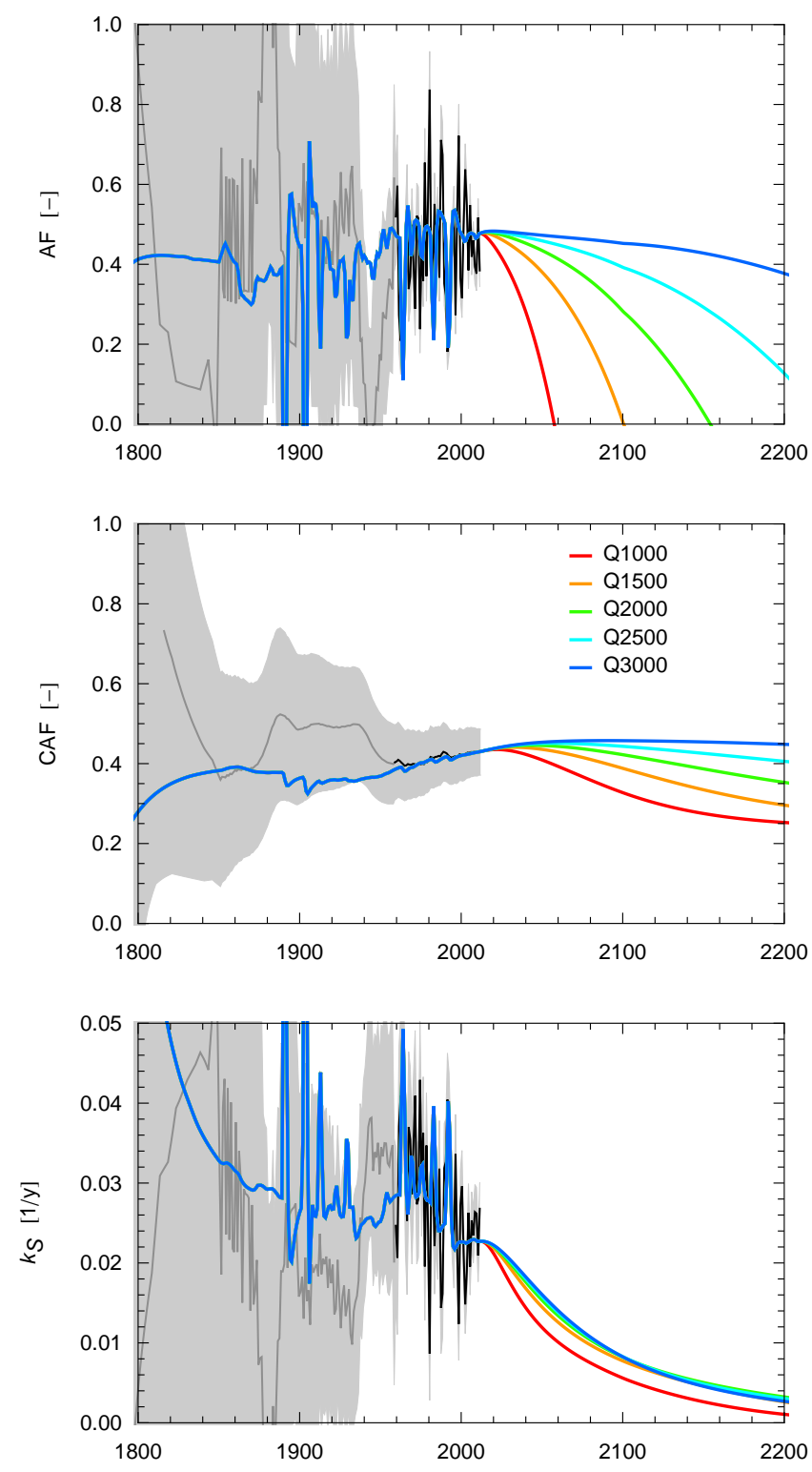

Fig. 7. SCCM predictions of $\mathrm{AF}, \mathrm{CAF}$ and $k_{\mathrm{S}}$ with analytic scenarios for future emissions of $\mathrm{CO}_{2}$ and non- $\mathrm{CO}_{2}$ gases $\left(\mathrm{CH}_{4}\right.$, $\mathrm{N}_{2} \mathrm{O}, \mathrm{CFCs}$ ) yielding cumulative total $\mathrm{CO}_{2}$ emissions $Q_{\mathrm{E}}(\infty)$ from 1000 to 3000 PgC. Model details as for Fig. 6. Error bands on observations are $\pm 1 \sigma$. Data sources: Appendix C.

responses of land-air and ocean-air $\mathrm{CO}_{2}$ exchanges, and the response of radiative forcing to gas concentrations. Model forcing is with prescribed emissions trajectories for $\mathrm{CO}_{2}$ and non- $\mathrm{CO}_{2}$ gases. The model also includes the response of terrestrial net primary production to volcanic eruptions, forced with an externally prescribed volcanic aerosol index. SCCM can be linearised analytically, by determining the model Jacobian and thence forming a tangent linear model. The eigenvalues $\lambda^{(m)}$ of $\mathbf{K}$ (the negative of the model Jacobian, from
Eq. A2) are indeed all positive, confirming that the model is dynamically stable.

To characterise model performance, Fig. 6 shows SCCM predictions for $\mathrm{CO}_{2}$ concentration $\left[\mathrm{CO}_{2}\right]$ and temperature $T$, with forcing from observed past emissions and analytic scenarios for future emissions of $\mathrm{CO}_{2}, \mathrm{CH}_{4}, \mathrm{~N}_{2} \mathrm{O}$ and CFCs. Future total $\mathrm{CO}_{2}$ emissions $f_{\mathrm{E}}(t)$ (top row of Fig. 6) are prescribed using a smooth analytic peak-and-decline trajectory (Raupach et al., 2011) such that the all-time cumulative total $\mathrm{CO}_{2}$ emission $Q_{\mathrm{E}}(\infty)$ takes values from 1000 to $3000 \mathrm{PgC}$ in $500 \mathrm{PgC}$ steps. Here $Q_{\mathrm{E}}(\infty)=1000 \mathrm{PgC}$ yields a strongmitigation trajectory for $\mathrm{CO}_{2}$ emissions akin to Representative Concentration Pathway (RCP) scenario RCP3pd (Moss et al., 2010; van Vuuren et al., 2011), and $Q_{\mathrm{E}}(\infty)=3000 \mathrm{PgC}$ yields a trajectory akin to the Special Report on Emissions Scenarios (SRES) A1B scenario (Nakicenovic et al., 2000). Emission trajectories for other gases are the same across all cases in Fig. 6 (see Appendix B for details). The left panels in Fig. 6 show plots of $f_{\mathrm{E}}(t),\left[\mathrm{CO}_{2}\right](t)$ and $T(t)$ against time $t$, while the right panels show the same quantities plotted against a different clock, cumulative $\mathrm{CO}_{2}$ emissions $Q_{\mathrm{E}}(t)$ defined by Eq. (10), to yield trajectories $f_{\mathrm{E}}\left(Q_{\mathrm{E}}\right),\left[\mathrm{CO}_{2}\right]\left(Q_{\mathrm{E}}\right)$ and $T\left(Q_{\mathrm{E}}\right)$.

Figure 6 shows broad agreement between SCCM predictions and past observations of $\left[\mathrm{CO}_{2}\right]$ and $T$. For the future, predictions for $\left[\mathrm{CO}_{2}\right]$ as a function of $Q_{\mathrm{E}}$ (Fig. 6, middle right panel) are close to straight lines up to near the time of the peak in $\mathrm{CO}_{2}$, and decline thereafter. (A linear relationship $\left[\mathrm{CO}_{2}\right]\left(Q_{\mathrm{E}}\right)$ is equivalent to a constant $\left.\mathrm{CAF}=c_{\mathrm{A}} / Q_{\mathrm{E}}\right)$. Predictions for $T$ as a function of $Q_{\mathrm{E}}$ (Fig. 6, lower right panel) fall close to a straight line with slope $T / Q_{\mathrm{E}}$ about $1.8 \mathrm{~K} \mathrm{EgC}^{-1}$, broadly consistent with the observed past behaviour for this relationship (Fig. 5) and with Eq. (15). The different behaviours of $\left[\mathrm{CO}_{2}\right]\left(Q_{\mathrm{E}}\right)$ and $T\left(Q_{\mathrm{E}}\right)$ beyond the time of peak $\mathrm{CO}_{2}$ arise because temperature $T$ declines from its peak much more slowly than $\mathrm{CO}_{2}$ (Raupach et al., 2011).

In Fig. 6 (lower right panel), present predictions for $T\left(Q_{\mathrm{E}}\right)$ are compared with projections from two model ensembles: the models used in the Fourth Assessment of the Intergovernmental Panel on Climate Change (IPCC AR4) (IPCC, 2007), and 11 coupled carbon-climate models in the C4MIP intercomparison (Friedlingstein et al., 2006; Matthews et al., 2009). The IPCC AR4 projections included forcing from multiple gases but no interactive carbon cycle, while the C4MIP projections used forcing from $\mathrm{CO}_{2}$ only but included an interactive carbon cycle. Present predictions fall within the envelopes of both model ensembles. Differences between the ensembles are assessed below (Sect. 4.2, Fig. 8).

Figure 7 shows SCCM predictions of AF, CAF and the $\mathrm{CO}_{2}$ sink rate $k_{\mathrm{S}}$, with the same forcing as for Fig. 6. The model reproduces observed past behaviour for all three quantities, apart from interannual variability that is not in the model and is known to be correlated with ENSO (Keeling and Revelle, 1985; Raupach et al., 2008). In the future, the 
predicted $\mathrm{AF}$ varies strongly with $\mathrm{CO}_{2}$ emissions, decreasing progressively more rapidly as $Q_{\mathrm{E}}(\infty)$ decreases, and becoming negative when the $\mathrm{CO}_{2}$ concentration starts to decline (Fig. 6, middle row). The CAF is much less variable but still responds to changes in $Q_{\mathrm{E}}(\infty)$, increasing slightly in future for the high-emission scenario $\left(Q_{\mathrm{E}}(\infty)=3000 \mathrm{PgC}\right)$ and decreasing for the lowest-emission scenario $(1000 \mathrm{PgC})$, with the decrease occurring mainly beyond the time of peak $\mathrm{CO}_{2}$, consistent with Fig. 6 (middle right panel). The sink rate $k_{\mathrm{S}}$ declines strongly in all future predictions, by a factor of order 3 from 2000 to 2100 and with further decreases thereafter, continuing a trend already evident in past observations (Fig. 4).

\subsection{Attribution of future departures from LinExp}

Under the LinExp idealisation, $\mathrm{AF}, \mathrm{CAF}, k_{\mathrm{S}}$ and $T / Q_{\mathrm{E}}$ would all be constant, with $\mathrm{AF}=\mathrm{CAF}$ (Eq. 13). For future trajectories of $\mathrm{AF}, \mathrm{CAF}$ and $k_{\mathrm{S}}$ this is clearly far from the case (Fig. 7), while for $T / Q_{\mathrm{E}}$, approximate constancy is observed (Fig. 6, lower right panel). To diagnose the reasons for these quite different behaviours, Fig. 8 shows predictions for $\mathrm{CO}_{2}$ concentration and global temperature $(T)$ from five versions of SCCM at a sequence of levels of simplification ranging from the full nonlinear model to the LinExp idealisation. The same forcing (the high-emission case $Q_{\mathrm{E}}(\infty)=3000 \mathrm{PgC}$ in Fig. 6) is used in every version except the last. Schematically, the components in the five model versions are

$$
\begin{aligned}
& \text { V1(fullmodel) }: \begin{array}{l}
\text { LinExp }+ \text { NonExp }+ \text { NonLin } \\
+ \text { Coupling }+\mathrm{NonCO}_{2}
\end{array} \\
& \begin{aligned}
\text { V2 }\left(\mathrm{CO}_{2} \text { only) }:\right. & \text { LinExp }+ \text { NonExp }+ \text { NonLin } \\
& + \text { Coupling }
\end{aligned} \\
& \text { V3(uncoupled) }: \text { LinExp }+ \text { NonExp }+ \text { NonLin }
\end{aligned}
$$

V4 (Lin) : LinExp + NonExp

V5 (LinExp) : LinExp.

Version 1 (full model) includes all processes represented in SCCM. V2 $\left(\mathrm{CO}_{2}\right.$ only) removes radiative forcing from non- $\mathrm{CO}_{2}$ gases and aerosols. V3 (uncoupled) also removes carbon-climate coupling arising from the dependence of $\mathrm{CO}_{2}$ fluxes on global temperature (a surrogate for all dependencies of fluxes on physical climate). V4 (Lin) is a fully linearised counterpart of $\mathrm{V} 3$ in which all equations for $\mathrm{CO}_{2}$ fluxes and $\mathrm{CO}_{2}$ radiative forcing have been linearised, and volcanic influences on the carbon cycle removed. V5 (LinExp) uses the same linearised model as V4, but with an exponential $\mathrm{CO}_{2}$ emissions trajectory $f_{\mathrm{E}}(t)$.

Considering first the trajectories of $\left[\mathrm{CO}_{2}\right]$ and $T$ as functions of time (left panels in Fig. 8), the prediction for $\left[\mathrm{CO}_{2}\right]$ shows little response to the removal of non- $\mathrm{CO}_{2}$ forcing (the step from V1 to V2) except beyond 2100 when warming is large and some decrease in $\left[\mathrm{CO}_{2}\right]$ is observed because of carbon-climate coupling. The same simplification step yields a comparable relative decrease in perturbation $T$ (Fig. 8, lower left panel). The removal of carbon-climate coupling (step V2 to V3) has a large effect on both $\left[\mathrm{CO}_{2}\right]$ and $T$, decreasing predicted $\left[\mathrm{CO}_{2}\right]$ by over $100 \mathrm{ppm}$ (680 to 550) in 2100 with larger decreases thereafter, and decreasing $T$ by a further $0.5 \mathrm{~K}$ in 2100 and $1 \mathrm{~K}$ in 2200 , on top of the decrease from V1 to V2. These changes in $\left[\mathrm{CO}_{2}\right]$ and $T$ in response to carbon-climate coupling fall within the wide range of responses found in carbon-climate model intercomparisons using high emission scenarios (Friedlingstein et al., 2006; Sitch et al., 2008). The effect of linearisation of $\mathrm{CO}_{2}$ dynamics and radiative forcing (step V3 to V4) is a moderate additional decrease in $\left[\mathrm{CO}_{2}\right]$ and a small additional decrease in $T$. Finally, imposing an exponential rather than a peak-and-decline $\mathrm{CO}_{2}$ emissions trajectory (step V4 to V5) has a large effect on both $\left[\mathrm{CO}_{2}\right]$ and $T$, producing exponentially growing perturbation $\left[\mathrm{CO}_{2}\right]$ and $T$ in accordance with the above theoretical results for a LinExp system.

The picture is different when trajectories of $\left[\mathrm{CO}_{2}\right]$ and $T$ are plotted against cumulative emissions $Q_{\mathrm{E}}(t)$ (right panels in Fig. 8). Using this clock (as in the right panels of Fig. 6), the full model (V1) produces trajectories $\left[\mathrm{CO}_{2}\right]\left(Q_{\mathrm{E}}\right)$ and $T\left(Q_{\mathrm{E}}\right)$ that are close to straight lines. The behaviour of $T\left(Q_{\mathrm{E}}\right)$ with the full model replicates Fig. 6 (lower right panel). For $\left[\mathrm{CO}_{2}\right]\left(Q_{\mathrm{E}}\right)$, near-straight-line behaviour is observed up to times a little before the peak in $\left[\mathrm{CO}_{2}\right]$, but not thereafter (Raupach et al., 2011) (compare with Fig. 6, middle right panel); this behaviour fills the whole of Fig. 8 (middle right panel) because the peak in $\mathrm{CO}_{2}$ occurs far in the future (well after 2300) under the high-emission scenario used. As the model is simplified sequentially from V1 to $\mathrm{V} 4$, the trajectories $\left[\mathrm{CO}_{2}\right]\left(Q_{\mathrm{E}}\right)$ and $T\left(Q_{\mathrm{E}}\right)$ fall progressively below the approximate straight lines for V1, in increments similar to those seen in the corresponding plots against time. The last simplification to reach the LinExp idealisation (V5) yields straight-line trajectories for both $\left[\mathrm{CO}_{2}\right]\left(Q_{\mathrm{E}}\right)$ and $T\left(Q_{\mathrm{E}}\right)$, consistent with theory (Eq. 12). These trajectories are close to those predicted by the full model (V1).

Also shown in Fig. 8 (lower right panel) are estimates of $T\left(Q_{\mathrm{E}}\right)$ from the IPCC AR4 and C4MIP projections, as in Fig. 6. The C4MIP projections used forcing from $\mathrm{CO}_{2}$ only with a coupled carbon cycle, and so correspond with model V2 above, while the IPCC AR4 projections included multigas forcing but no carbon-climate coupling, and so do not correspond with any of V1 to V5. Values of $T\left(Q_{\mathrm{E}}\right)$ from the C4MIP projections tend to lie below those from IPCC AR4 projections, and scatter around the prediction for model V2 (orange line) in Fig. 8.

In summary, near-linear behaviour for the trajectories $\left[\mathrm{CO}_{2}\right]\left(Q_{\mathrm{E}}\right)$ and $T\left(Q_{\mathrm{E}}\right)$ is observed at both ends of the model simplification sequence, the full model (V1) and the LinExp idealisation (V5). However, the reasons are quite different in each case. In the LinExp idealisation, linear behaviour is a theoretical requirement following from the fact 

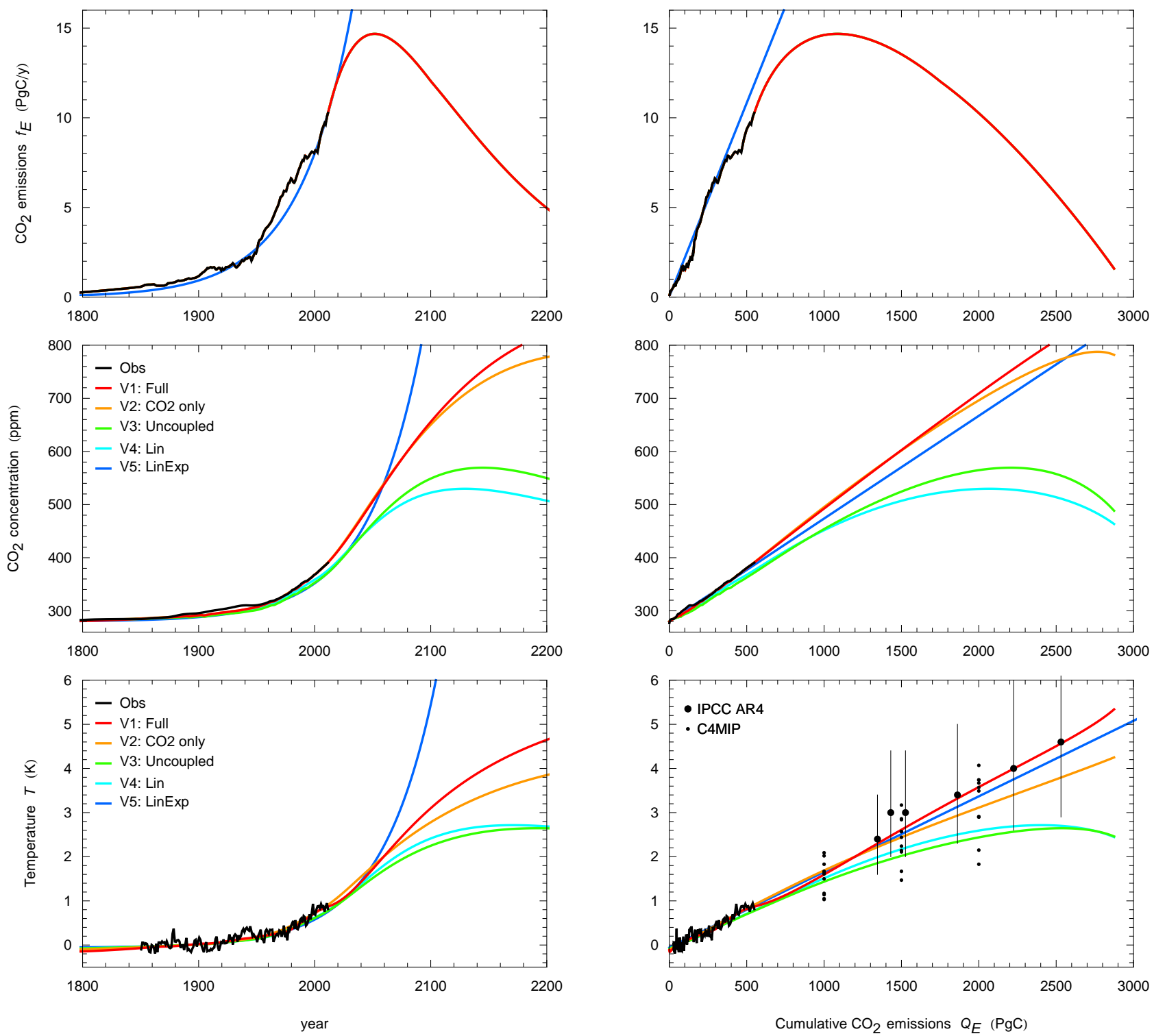

Fig. 8. SCCM predictions of $\left[\mathrm{CO}_{2}\right]$ and $T$ with successive simplification of process descriptions, from a full model to the LinExp idealisation. Model versions: (V1, red) full model; (V2, orange) $\mathrm{CO}_{2}$ only; (V3, green) uncoupled; (V4, sky blue) Lin; (V5, dark blue) LinExp. Prescribed total $\mathrm{CO}_{2}$ emissions trajectories are identical for versions V1 to V4 (the case $Q_{\mathrm{E}}(\infty)=3000 \mathrm{PgC}$ in Fig. 6), and are exponential for V5. Other details as for Fig. 6. Data sources: Appendix C.

that a linear system has exponential eigenmodes, so that all ratios among state variables and fluxes are constant when forcing is exponential. For the full model, near-linear behaviour of $\left[\mathrm{CO}_{2}\right]\left(Q_{\mathrm{E}}\right)$ and $T\left(Q_{\mathrm{E}}\right)$ arises from compensations between opposing nonlinear effects from (1) positive feedbacks from carbon-climate coupling (tending to increase the $\mathrm{CAF}$ and increase the upward curvature or reduce the downward curvature in $\left[\mathrm{CO}_{2}\right]\left(Q_{\mathrm{E}}\right)$ and $\left.T\left(Q_{\mathrm{E}}\right)\right)$; (2) the response of $\mathrm{CO}_{2}$ radiative forcing (weakening with increasing $\mathrm{CO}_{2}$ and hence tending to make $T\left(Q_{\mathrm{E}}\right)$ curve downward); and (3) non- $\mathrm{CO}_{2}$ radiative forcing (tending to make $T\left(Q_{\mathrm{E}}\right)$ curve upward as net non- $\mathrm{CO}_{2}$ radiative forcing becomes pro- gressively more positive). The first two of these effects were identified by Matthews et al. (2009) as contributors to the near-linear behaviour of $T\left(Q_{\mathrm{E}}\right)$. Without all three effects, $\left[\mathrm{CO}_{2}\right]\left(Q_{\mathrm{E}}\right)$ and $T\left(Q_{\mathrm{E}}\right)$ would both be nonlinear under realistic, non-exponential peak-and-decline emissions trajectories curving downwards below straight-line behaviour as in model V4 (Fig. 8, right panels). When these effects are included (model V1), the resulting net increases in $\left[\mathrm{CO}_{2}\right]\left(Q_{\mathrm{E}}\right)$ and $T\left(Q_{\mathrm{E}}\right)$ restore approximate straight-line behaviour.

Figure 9 shows the effect of model simplification on the $\mathrm{AF}, \mathrm{CAF}$ and the $\mathrm{CO}_{2}$ sink rate $k_{\mathrm{S}}$. In the simplification sequence from $\mathrm{V} 1$ to $\mathrm{V} 4$, the largest effect occurs with the 

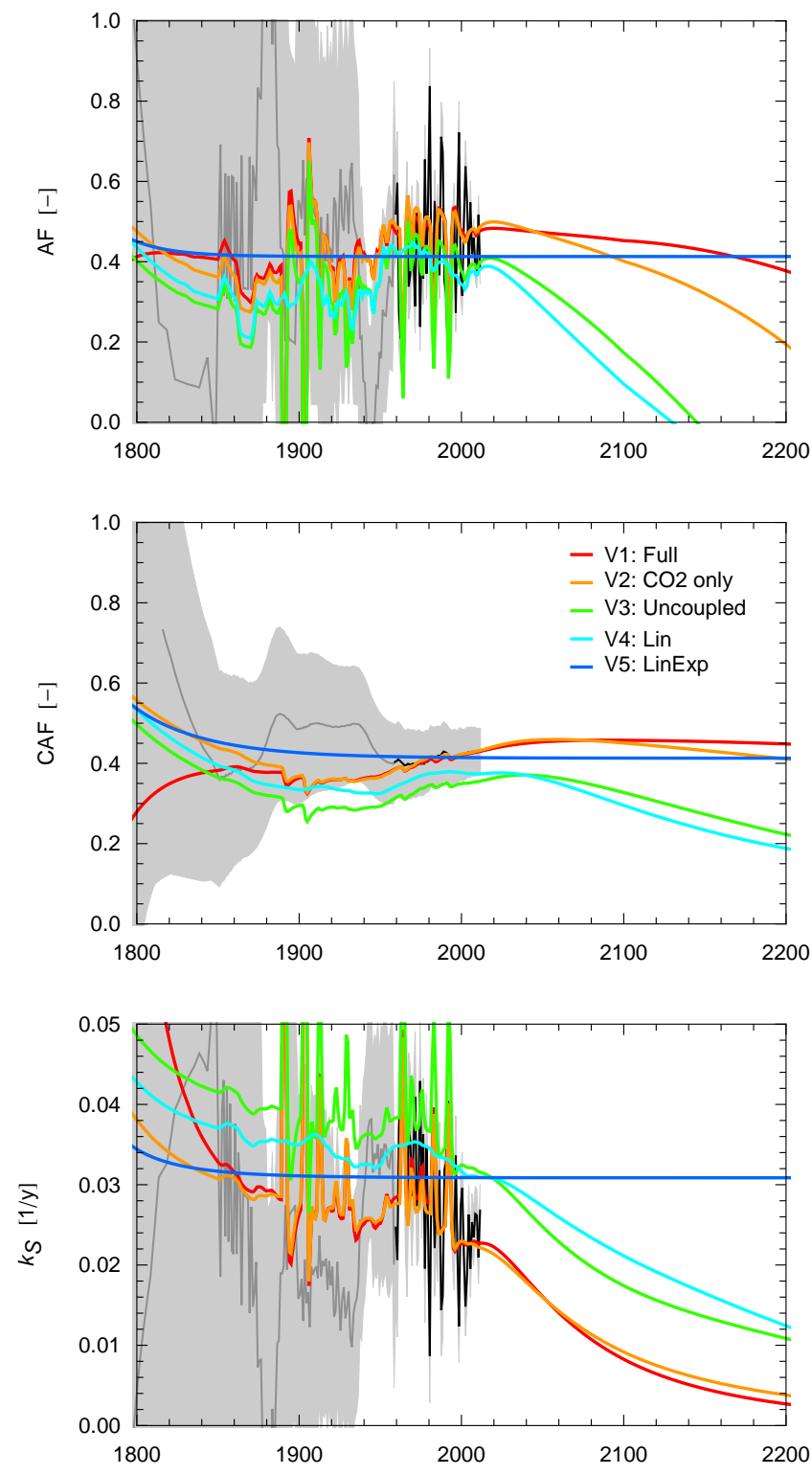

Fig. 9. SCCM predictions of AF, CAF and $k_{\mathrm{S}}$ with successive simplification of process descriptions, from a full model to the LinExp idealisation. Model details as for Fig. 8. Error bands on observations are $\pm 1 \sigma$. Data sources: Appendix C.

removal of nonlinear carbon-climate coupling (V2 to V3), causing the AF to decrease strongly and changing both the level and trend in the CAF and $k_{\mathrm{S}}$. When the LinExp idealisation is reached (V5), constant values for all three quantities are obtained in accordance with theory.

\section{Conclusions}

The LinExp idealisation provides useful guidance about the past behaviour of the carbon-climate system under strong anthropogenic forcing from 1850 to present, explaining the observed near-constancy of the airborne fraction (AF), the cumulative airborne fraction (CAF) and the ratio $T / Q_{\mathrm{E}}$ of warming to cumulative $\mathrm{CO}_{2}$ emissions. This idealisation is relevant for the past because three conditions have been approximately satisfied: (1) total $\mathrm{CO}_{2}$ emissions have increased nearly exponentially (Fig. 1); (2) linearity of carbon cycle response fluxes has been a reasonable approximation (implying that land and ocean sink fluxes have been approximately proportional to excess $\mathrm{CO}_{2}$ concentration); and (3) there has been approximate cancellation in recent times of the two major classes of radiative forcing other than $\mathrm{CO}_{2}$, the positive forcing from long-lived non- $\mathrm{CO}_{2}$ gases $\left(\mathrm{CH}_{4}, \mathrm{~N}_{2} \mathrm{O}\right.$ and synthetic gases), and the negative forcing from other agents (mainly aerosols, ozone and albedo effects) (IPCC, 2007, their Fig. 2.4)

Nevertheless, departures from the LinExp predictions of constant $\mathrm{AF}, \mathrm{CO}_{2}$ sink rate $\left(k_{\mathrm{S}}\right)$ and $T / Q_{\mathrm{E}}$ are already evident in past observations, particularly in the observed decrease of $k_{\mathrm{S}}$. These departures will increase as all three of the above conditions break down progressively: (1) emissions will depart from present near-exponential growth (Fig. 1) if mitigation efforts cause trajectories to peak and decline; (2) linearity of carbon cycle responses is likely to be disrupted by increasing nonlinearities as perturbations become larger; (3) the approximate cancellation of non- $\mathrm{CO}_{2}$ contributions to radiative forcing is unlikely to continue, because of declining negative forcing from non-gaseous agents and increased forcing from non- $\mathrm{CO}_{2}$ gases (Strassmann et al., 2009; Meinshausen et al., 2011; IIASA, 2012).

The predicted net effect of these factors is that the AF and $k_{\mathrm{S}}$ will depart strongly from constancy in ways that depend on emissions scenarios (Fig. 7): for example, the AF will become negative late in the 21 st century under strong mitigation scenarios. However, the predicted ratio $T / Q_{\mathrm{E}}$ continues to be approximately constant in typical scenarios (Fig. 6). This is not because of continued applicability of the LinExp idealisation, but instead because of compensating interactions between non-exponential emissions trajectories, nonlinear carbon-cycle dynamics and non- $\mathrm{CO}_{2}$ gases.

Nonlinear effects needing further investigation include potential threshold crossings not yet evident in the carbonclimate system, typically associated with regional triggers that have global consequences. Examples include large carbon releases from thawing permafrost soils (Schuur et al., 2008; Tarnocai et al., 2009; MacDougall et al., 2012), major changes in ocean circulation, and loss of the arctic ice sheet through warming. Processes associated with these thresholdlike reinforcing feedbacks are not in the model (SCCM) used here, so present conclusions about the future effects of nonlinearities may be conservative. 


\section{Appendix A}

\section{Mathematical details}

\section{A1 Linearised model}

Equation (1) is a general representation of a carbon-climate model in which $\boldsymbol{x}(t)$ is a carbon-climate state vector of matter and energy stores (taken as a perturbation about an equilibrium state $\boldsymbol{x}=0), \boldsymbol{f}(t)$ a vector of anthropogenic forcing fluxes, $\boldsymbol{\Phi}(\boldsymbol{x})$ a vector of system response fluxes, and $t$ time. The state vector $\boldsymbol{x}$ includes a set of carbon stores in atmospheric, land and ocean reservoirs, a set of physical climate state variables such as land and ocean temperatures and atmospheric water contents. The forcing flux vector $f(t)$ is externally prescribed. The response flux vector $\boldsymbol{\Phi}(\boldsymbol{x})$ is the set of net fluxes into the different stores $(\boldsymbol{x})$ arising from the response of the system to forcing, and is specified by nonlinear "phenomenological equations" embodying model parameterisations.

The equation system (Eq. 1) can be linearised by approximating $\boldsymbol{\Phi}(\boldsymbol{x})$ as

$$
\boldsymbol{\Phi}(\boldsymbol{x})=\boldsymbol{\Phi}_{0}-\mathbf{K}\left(\boldsymbol{x}-\boldsymbol{x}_{0}\right)
$$

where $\boldsymbol{x}_{0}=\boldsymbol{x}(0)$ is the linearisation point (referenced to $t=0), \boldsymbol{\Phi}_{0}=\boldsymbol{\Phi}\left(\boldsymbol{x}_{0}\right)$, and $\mathbf{K}$ is the system response matrix, the negative of the Jacobian matrix of $\boldsymbol{\Phi}(\boldsymbol{x})$ :

$K_{i j}=-\left[\partial \varphi_{i} / \partial x_{j}\right]_{x=x_{0}}$.

Diagonal elements of $\mathbf{K}$ are rate constants for flows out of store $i=j$. The linearisation point $\boldsymbol{x}_{0}$ is arbitrary, the simplest option (used in the main text) being to take $\boldsymbol{x}_{0}$ as the initial equilibrium state $\left(\boldsymbol{x}_{0}=0, \boldsymbol{\Phi}_{0}=0\right)$.

With arbitrary $\boldsymbol{x}_{0}$, Eq. (1) becomes

$\mathrm{d} \boldsymbol{x} / \mathrm{d} t=\boldsymbol{f}(t)+\boldsymbol{\Phi}_{0}-\mathbf{K}\left(\boldsymbol{x}-\boldsymbol{x}_{0}\right)$

with initial condition $\boldsymbol{x}(0)=\boldsymbol{x}_{0}$ and with $\boldsymbol{\Phi}_{0}=\boldsymbol{\Phi}\left(\boldsymbol{x}_{0}\right)$. The solution is

$\boldsymbol{x}(t)=\int_{0}^{t} \mathbf{G}(t-\tau)\left[\boldsymbol{f}(\tau)+\boldsymbol{\Phi}_{0}+\mathbf{K} \boldsymbol{x}_{0}\right] \mathrm{d} \tau$

where the matrix PRF or Green's function is

$\mathbf{G}(t)=\exp (-\mathbf{K} t)$

using the matrix exponential $\exp (\mathbf{M})$, defined for a square matrix $\mathbf{M}$ by

$\exp (\mathbf{M})=\sum_{n=0}^{\infty} \frac{\mathbf{M}^{n}}{n !}$

Equations (A3) and (A4) generalise main-text Eqs. (2) and (3) to arbitrary $\boldsymbol{x}_{0}$.
Equation (A4) is the multi-dimensional counterpart of the solution for a one-dimensional linear ordinary differential equation (LODE) with constant coefficients:

$\mathrm{d} x / \mathrm{d} t=f(t)-k x$ with $\quad x(0)=x_{0}$.

Here $\exp (\mathbf{K} t)$ reduces to the scalar exponential $e^{-k t}$, yielding the conventional solution

$x(t)=\int_{0}^{t} e^{-k(t-\tau)} f(\tau) \mathrm{d} \tau+e^{-k t} x_{0}$.

\section{A2 Normal modes}

In the linear system of Eq. (2), let the system response matrix $\mathbf{K}$ have eigenvalues $\lambda^{(m)}$ and eigenvectors $\boldsymbol{u}^{(m)}$ for modes $m$, so that

$\mathbf{K} \boldsymbol{u}^{(m)}=\boldsymbol{u}^{(m)} \lambda^{(m)}, \quad \mathbf{K}=\mathbf{U} \Lambda \mathbf{U}^{-1}$

where $\mathbf{U}$ is the matrix of column eigenvectors of $\mathbf{K}$, and $\Lambda=\operatorname{diag}\left(\lambda^{(m)}\right)$ is the diagonal matrix of its eigenvalues. In terms of components $u_{i}^{(m)}$ of the eigenvectors, components of $\mathbf{U}$ are $U_{i m}=u_{i}^{(m)}$. The matrices $\mathbf{K}, \mathbf{U}$ and $\Lambda$ are all square and of the same dimension, and $\mathbf{U}^{-1}$ is a rotation matrix that maps $\mathbf{K}$ to the diagonal matrix $\Lambda$. This matrix also maps the state vector $\boldsymbol{x}(t)$ to a new state vector $\boldsymbol{y}(t)$ of normal modes, such that

$\boldsymbol{y}=\mathbf{U}^{-1} \boldsymbol{x}, \quad \boldsymbol{x}=\mathbf{U} \boldsymbol{y}$.

(A10)

Restricting to $\boldsymbol{x}_{0}=0$ (the more general case is similar), Eq. (2) can be rotated to the new reference frame by premultiplying by $\mathbf{U}^{-1}$ :

$\mathrm{d} \boldsymbol{y} / \mathrm{d} t=\mathbf{U}^{-1} \boldsymbol{f}(t)-\Lambda \boldsymbol{y}$ with $\boldsymbol{y}(0)=0$.

For the diagonal matrix $\Lambda, \exp (\Lambda)=\operatorname{diag}\left(\exp \lambda^{(m)}\right)$, so Eq. (A11) is a set of independent scalar equations like Eq. (A7) that can be solved one by one. The solution for $\boldsymbol{y}(t)$ is

$\boldsymbol{y}(t)=\int_{0}^{t} \exp (-\Lambda(t-\tau)) \mathbf{U}^{-1} \boldsymbol{f}(\tau) \mathrm{d} \tau$.

Using Eq. (A10), the corresponding solution for $\boldsymbol{x}(t)$ is

$\boldsymbol{x}(t)=\int_{0}^{t} \mathbf{U} \exp (-\Lambda(t-\tau)) \mathbf{U}^{-1} \boldsymbol{f}(\tau) \mathrm{d} \tau$.

This is consistent with the direct solution, Eqs. (A4) and (A5), because the PRF is

$\mathbf{G}(t)=\exp (-\mathbf{K} t)=\mathbf{U} \exp (-\Lambda t) \mathbf{U}^{-1}$ 
using Eqs. (A6) and (A9).

Equation (A14) shows that the elements of $\mathbf{G}(t)$ are sums of exponential terms with decay rates for different modes $(m)$ given by the eigenvalues $\lambda^{(m)}$ of $\mathbf{K}$ :

$G_{i j}(t)=\sum_{m} a_{i j}^{(m)} \exp \left(-\lambda^{(m)} t\right)$

with

$a_{i j}^{(m)}=U_{i m}\left(U^{-1}\right)_{m j}$

(also see Eq. 5). The weights $a_{i j}^{(m)}$ sum over $m$ to 1 when $i=j$ and to 0 otherwise, because $\mathbf{U} \mathbf{U}^{-1}=\mathbf{I}$, the identity matrix. This ensures that $\mathbf{G}(0)=\mathbf{I}$, as required for a PRF.

Equations (A13) to (A15) yield a solution for $\boldsymbol{x}(t)$ as a sum of convolution integrals with exponential kernels. It is often more useful to compute $\boldsymbol{x}(t)$ from solutions of independent LODEs, by letting $z_{i}^{(m)}=U_{i m} y_{m}$ (no sum), a set of rescaled versions of the normal modes $y_{m}$. The $z_{i}^{(m)}$ are governed by a set of independent LODEs:

$\frac{\mathrm{d} z_{i}^{(m)}}{\mathrm{d} t}=\sum_{j} a_{i j}^{(m)} f_{j}(t)-\lambda^{(m)} z_{i}^{(m)}$.

The rescaled normal modes sum to $x_{i}(t)=\sum_{m} z_{i}^{(m)}$.

\section{A3 Eigenmodes}

With a linear operator $L(\boldsymbol{x}(t))$, a general inhomogeneous linear system with forcing $\boldsymbol{f}(t)$ is

$L(\boldsymbol{x}(t))=\boldsymbol{f}(t)$.

The eigenmodes (eigenvalues $\alpha$ and eigenfunctions $\boldsymbol{v}(t)$ ) of this system satisfy

$L(\boldsymbol{v}(t))=\alpha \boldsymbol{v}(t)$.

For the first-order linear system (Eq. 2), the operator $L(\boldsymbol{x}(t))$ is given by Eq. (6).

The eigenfunctions of this first-order linear system are exponentials in time. This is demonstrated first for onedimensional and then for multi-dimensional cases.

One dimension: in the scalar case, the linear system is governed by Eq. (A7) and its eigenfunctions satisfy $\mathrm{d} v / \mathrm{d} t+k v=\alpha v$, or $\mathrm{d}(\ln v) / \mathrm{d} t=\alpha-k$. This implies that

$v(t)=c e^{(\alpha-k) t}$,

where $c$ is an arbitrary constant. Equation (A20) is an eigenfunction of Eq. (A7) with any eigenvalue $\alpha$ and constant $c$. Since these eigenfunctions are exponential, any exponential forcing produces a proportional exponential response. If the forcing for the scalar system is $f(t)=f_{0} e^{r t}$, an exponential with growth rate $r$, then the eigenfunction selected by this forcing is given by $L(\boldsymbol{v}(t))=f(t)=\alpha \boldsymbol{v}(t)$, or

$f_{0} e^{r t}=\alpha c e^{(\alpha-k) t}$,

which requires that $r=\alpha-k$ and $f_{0}=\alpha c$, so that $c=f_{0} /(r+$ $k$ ). The resulting eigenfunction is therefore

$v(t)=\frac{f_{0}}{r+k} e^{r t}$.

This can be compared with the full solution of Eq. (A7) with $f(t)=f_{0} e^{r t}$ :

$x(t)=\frac{f_{0}}{r+k} e^{r t}+\left(x_{0}-\frac{f_{0}}{r+k}\right) e^{-k t}$.

This solution is the sum of the exponential eigenfunction $v(t)$ given by Eq. (A22), and a decaying transient term (taking $k>0$ ) that accounts for any difference between the initial condition $x(0)=x_{0}$ and the initial eigenfunction $v(0)=f_{0} /(r+k)$. For any initial condition, the full solution approaches the eigenfunction (Eq. A22). The fact that any exponential function is an eigenfunction means that an exponential forcing produces an exponential response with the same growth rate as the forcing.

Multiple dimensions: the eigenfunctions for a multidimensional system are easily identified after rotating the state vector $\boldsymbol{x}(t)$ and its governing system (Eq. 2) to form normal modes $\boldsymbol{y}(t)$ governed by Eq. (A11). Because the normal modes are independent, the eigenfunctions for each mode $m$ are given by Eq. (A20) with a response rate $(k)$ equal to the eigenvalue $\lambda^{(m)}$ for that mode. When exponential forcing $\left(f(t)=f_{0} e^{r t}\right)$ is applied to that mode, the response is an exponential eigenfunction in that mode, given by Eq. (A22) with $k=\lambda^{(m)}$.

In multi-dimensional systems, forcing $(\boldsymbol{f})$ is applied to components of the state vector $(\boldsymbol{x})$ rather than to modes $(\boldsymbol{y})$. This forcing is distributed among modes as $\mathbf{U}^{-1} \boldsymbol{f}$ (Eq. A11). When the forcing is exponential, the result is an exponential response in multiple normal modes. An example is a system forced exponentially in just the first component of the state vector $\boldsymbol{x}$, so that

$\boldsymbol{f}=\left(f_{01} e^{r_{1} t}, 0,0, \ldots\right)$.

The resulting explicit solution for $\boldsymbol{x}(t)$ in multiple dimensions is the sum $\boldsymbol{x}(t)=\sum_{m} z_{i}^{(m)}(t)$ of independent scaled normal-mode solutions, each governed by Eq. (A17) and having a scalar solution given by Eq. (A23). Summing these solutions, the resulting $\boldsymbol{x}(t)$ is

$x_{i}(t)=\sum_{m}\left(\frac{a_{i 1}^{(m)} f_{01}}{r_{1}+\lambda^{(m)}}\right) e^{r_{1} t}+$ transient

transient $=\sum_{m}\left(\sum_{j} a_{i j}^{(m)} x_{j}(0)-\frac{a_{i 1}^{(m)} f_{01}}{r_{1}+\lambda^{(m)}}\right) e^{-\lambda^{(m)} t}$. 
As in the scalar solution, the first term is an exponentially growing eigenfunction and the second a decaying transient term. The weights $a_{i j}^{(m)}$ are given by Eq. (A15).

\section{A4 Ratios among fluxes and state variables}

Here it is shown that LinExp systems (first-order linear systems with exponential forcing) have the following properties: (a) all state variables grow at forcing rates, not response rates; (b) all ratios among state variables approach constant values; (c) all partition fractions (ratios of growth rates of state variables to the forcing flux) approach constant values; and (d) all ratios become independent of initial conditions at greater than forcing rates.

Property (a) is demonstrated by Eq. (A25). To demonstrate properties (b), (c) and (d), the one-dimensional and multidimensional cases are dealt with in turn.

One dimension: for the scalar case, Eq. (A7), the solution is Eq. (A8). This solution is characterised by two ratios: the partition fraction $x^{\prime}(t) / f(t)$, and the cumulative partition fraction $x(t) / Q(-\infty, t)$. Here $Q(-\infty, t)$ is the cumulative forcing

$$
Q(-\infty, t)=\int_{-\infty}^{t} f_{0} e^{r \tau} \mathrm{d} \tau=\frac{f_{0}}{r} e^{r t}
$$

From Eq. (A23), the partition fraction and the cumulative partition fraction are, respectively,

$$
\begin{aligned}
& \frac{x^{\prime}(t)}{f(t)}=\frac{r}{r+k}-\left(\frac{k x_{0}}{f_{0}}-\frac{k}{r+k}\right) e^{-(r+k) t} \\
& \frac{x(t)}{Q(-\infty, t)}=\frac{r}{r+k}+\left(\frac{r x_{0}}{f_{0}}-\frac{k}{r+k}\right) e^{-(r+k) t} .
\end{aligned}
$$

Both ratios approach the constant value $r /(r+k)$ (equal to $r / \alpha)$ with a transient term decaying at the rate $r+k$. When $r$ and $k$ are both positive, the decay rate of the transient term is larger than both the forcing rate $(r)$ and the response rate $(k)$.

Multiple dimensions: in this case the partition fractions for the system are the fractions of the forcing flux appearing instantaneously in the stores $x_{i}(t)$, and the cumulative partition fractions are the ratios of the stores themselves to cumulative forcing. For a system forced exponentially in just the first component of the state vector $\boldsymbol{x}$ (Eq. A24), the partition fractions are

$\frac{x_{i}^{\prime}(t)}{f_{1}(t)}=\sum_{m} \frac{a_{i 1}^{(m)} f_{01}}{r_{1}+\lambda^{(m)}}+$ transient

transient

$=-\sum_{m}\left(\frac{\lambda^{(m)}}{f_{01}} \sum_{j} a_{i j}^{(m)} x_{j}(0)-\frac{a_{i 1}^{(m) \lambda^{(m)}}}{r_{1}+\lambda^{(m)}}\right) e^{-\left(r_{1}+\lambda^{(m)}\right) t}$.

This generalises Eq. (A27). As before, a constant plus a decaying transient term are obtained. The cumulative partition fractions are given by a similar expression with the same constant term, as in Eq. (A28). These equations verify properties (b), (c) and (d) for LinExp systems.

\section{A5 Sink rate}

Here it is shown that the sink rate $k_{\mathrm{S}}$ defined by Eq. (14) is a time-dependent weighted mean of the turnover rates in the carbon cycle. In a general linear, multi-pool model of the carbon cycle, the excess carbon $c_{i}(t)$ in pool $i$ is governed by Eq. (2). As in Appendix A2, the variables $c_{i}(t)$ can be transformed to new variables $z_{i}^{(m)}(t)$ (the rescaled normal modes) governed by Eq. (A17), such that $c_{i}(t)=\sum_{m} z_{i}^{(m)}$. Let pool $c_{1}(t)$ be the atmospheric $\mathrm{CO}_{2}$ store and $f_{1}(t)$ the total anthropogenic $\mathrm{CO}_{2}$ emission flux into the atmosphere. The modes $z_{1}^{(m)}(t)$ summing to $c_{1}(t)$ are governed by Eq. (A17) with $i=1$ and $j=1$. Summing over modes $m$ and using Eq. (A16), it follows that $c_{1}(t)$ satisfies

$\frac{\mathrm{d} c_{1}}{\mathrm{~d} t}=f_{1}(t)-\sum_{m} \lambda^{(m)} z_{1}^{(m)}$

Using the definition of the sink rate $k_{\mathrm{S}}$ in Eq. (14), the last term in this equation (the total $\mathrm{CO}_{2}$ sink) can also be written as $k_{\mathrm{S}} c_{1}$. It follows that

$k_{\mathrm{S}}=\sum_{m} \beta^{(m)} \lambda^{(m)}$ with $\beta^{(m)}=z_{1}^{(m)} / c_{1}$.

Hence $k_{\mathrm{S}}$ is a weighted mean of the turnover rates for the modes $m$, with weights $\beta^{(m)}$ summing to 1 . These weights depend on time in general, because the modes $z_{1}^{(m)}$ grow at different rates. In the particular case where the forcing $f_{1}(t)$ is exponential (the LinExp idealisation), $\beta^{(m)}$ and $k_{\mathrm{S}}$ become constant in time.

\section{Appendix B}

\section{Simple Carbon-Climate Model}

The Simple Carbon-Climate Model (SCCM) (Raupach et al., 2011; Harman et al., 2011) is a globally aggregated model of the carbon-climate system, mainly based on well-established formulations.

The model state vector is $\left(c_{\mathrm{A}}, C_{\mathrm{L} 1}, C_{\mathrm{L} 2}, c_{\mathrm{Mi}}, c_{\mathrm{MD}},\left[\mathrm{CH}_{4}\right]\right.$, [ $\mathrm{N}_{2} \mathrm{O}$ ], [CFC-11], [CFC-12], $\left.T_{\mathrm{M} i}\right)$; it includes one atmospheric total carbon store $\left(c_{\mathrm{A}}\right)$, two land carbon stores $\left(C_{\mathrm{L} 1}\right.$, $C_{\mathrm{L} 2}$ ), four perturbation carbon stores in the ocean mixed layer $\left(c_{\mathrm{M} i}\right)$, one perturbation carbon store in the deep ocean $\left(c_{\mathrm{MD}}\right)$, atmospheric concentrations of four non- $\mathrm{CO}_{2}$ greenhouse gases, and three perturbation global temperatures $\left(T_{\mathrm{M} i}\right)$. Total and perturbation state variables are denoted by upper and lower-case letters, respectively, and the equilibrium (preindustrial) state by a subscript $q$ (so $\boldsymbol{X}$ and $\boldsymbol{X}_{q}$ are total and equilibrium state vectors, and $\boldsymbol{x}=\boldsymbol{X}-\boldsymbol{X}_{q}$ is the 
perturbation about the equilibrium state). An exception to this convention is temperature, where the absolute temperature is $\Theta$ and the perturbation temperature is $T=\Theta-\Theta_{q}$.

Atmospheric carbon: the mass balance for the atmospheric $\mathrm{CO}_{2}$ store is:

$c_{\mathrm{A}}^{\prime}=f_{\mathrm{Foss}}+f_{\mathrm{LUC}}+f_{\mathrm{L}}+f_{\mathrm{M}}$

where the prescribed forcing fluxes are $f_{\text {Foss }}(t)\left(\mathrm{CO}_{2}\right.$ emissions from fossil fuels and other industry) and $f_{\mathrm{LUC}}(t)$ (emissions from net land use change). The total emission is $f_{\mathrm{E}}=f_{\text {Foss }}+f_{\text {LUC }}$.

Land carbon: the land carbon stores $C_{\mathrm{L} 1}$ and $C_{\mathrm{L} 2}$ are the total carbon stores $[\mathrm{PgC}]$ in global fast and slow stores, respectively. The governing mass balance equations are

$\mathrm{d} C_{\mathrm{L} 1} / \mathrm{d} t=a_{\mathrm{L} 1} f_{\mathrm{NPP}}-k_{\mathrm{L} 1} C_{\mathrm{L} 1}$

$\mathrm{d} C_{\mathrm{L} 2} / \mathrm{d} t=a_{\mathrm{L} 2} f_{\mathrm{NPP}}-k_{\mathrm{L} 2} C_{\mathrm{L} 2}-f_{\mathrm{LUC}}$

where $f_{\mathrm{NPP}}$ is the global terrestrial net primary production (NPP) of biomass carbon $\left[\mathrm{PgC} \mathrm{yr}^{-1}\right], k_{\mathrm{Li}}$ is the respiration rate $\left[\mathrm{yr}^{-1}\right]$ for store $i$, and $a_{\mathrm{Li}}$ is the fraction of global NPP entering store $i$, with $a_{\mathrm{L} 1}+a_{\mathrm{L} 2}=1$. The respiration rates $k_{\mathrm{Li}}$ depend on the global temperature $\Theta$ through a $q_{10}$ parameter (the proportional increase in rate for each $10 \mathrm{~K}$ of warming). The land use change flux $f_{\mathrm{LUC}}$ is withdrawn from the slow land carbon store $C_{\mathrm{L} 2}$.

The terrestrial NPP $f_{\mathrm{NPP}}$ is a function of $\mathrm{CO}_{2}$ concentration, modulated by a factor dependent on the volcanic aerosol index (VAI) (Ammann et al., 2003) to account for the enhancement of terrestrial NPP by large volcanic eruptions, mainly through the increase in diffuse solar irradiance (Jones and Cox, 2001). The dependence on $\left[\mathrm{CO}_{2}\right]$ is modelled using a power-hyperbolic function $h(x)=x\left(x^{p}+x_{\mathrm{R}}^{p}\right)^{-1 / p}(x \geq 0)$, a function that aysmptotically approaches $x / x_{R}$ as $x \rightarrow 0$ and saturates to 1 as $x \rightarrow \infty$, with the power $p$ determining the tightness of the curve between the two asymptotes. This functional form allows both a near-linear response of NPP to increasing $\mathrm{CO}_{2}$ at low excess $\mathrm{CO}_{2}$, and a saturating response at high $\mathrm{CO}_{2}$. The model is

$f_{\mathrm{NPP}}=s_{1}\left(c_{\mathrm{A}}\right) s_{2}(\mathrm{VAI})$

with $s_{1}\left(c_{\mathrm{A}}\right)=f_{\mathrm{NPP}(q)}\left(1+\frac{\left(m_{\mathrm{NPP}}-1\right) c_{\mathrm{A}}}{\left(c_{\mathrm{A}}^{p}+c_{\mathrm{NPP}}^{p}\right)^{1 / p}}\right)$

and $s_{2}(\mathrm{VAI})=(1+0.5 \mathrm{VAI})$

where $f_{\mathrm{NPP}(q)}$ is preindustrial NPP, $m_{\mathrm{NPP}}$ is a multiplier for NPP (saturated/preindustrial), $c_{\mathrm{NPP}}$ is a slope parameter, and $p$ is a power parameter. Equation (B3) supplements several earlier options (Raupach et al., 2011; Harman et al., 2011). The factor $(1+0.5 \mathrm{VAI})$ accounts for the enhancement of NPP by volcanic aerosol.
The land-atmosphere exchange flux $f_{\mathrm{L}}$ is the negative terrestrial net ecosystem productivity (NEP):

$f_{\mathrm{L}}=-f_{\mathrm{NEP}}=-\left(f_{\mathrm{NPP}}-k_{\mathrm{L} 1} C_{\mathrm{L} 1}-k_{\mathrm{L} 2} C_{\mathrm{L} 2}\right)$.

Ocean carbon: perturbation carbon in the ocean mixed layer (as dissolved inorganic carbon, DIC) is the sum of several stores with different turnover rates $k_{C i}$ for carbon exchange with the deep ocean. A deep ocean carbon store tracks the carbon transferred downward out of the ocean mixed layer. Mass balances for these perturbation carbon stores are

$\mathrm{d} c_{\mathrm{M} i} / \mathrm{d} t=-a_{\mathrm{C} i} f_{\mathrm{M}}-k_{\mathrm{C} i} c_{\mathrm{M} i}$

$\mathrm{d} c_{\mathrm{MD}} / \mathrm{d} t=\sum_{i} k_{\mathrm{Ci}} c_{\mathrm{Mi}}$,

where $a_{\mathrm{C} i}$ is the fraction of the atmosphere-ocean $\mathrm{CO}_{2}$ flux entering store $i$, and $\sum a_{\mathrm{C} i}=1$ over all $i$. Equation (B5) is equivalent to a pulse-response-function (PRF) formulation for DIC in the ocean mixed layer (Joos et al., 1996; Raupach et al., 2011). The weights $a_{\mathrm{C} i}$ and rates $k_{\mathrm{C} i}$ are specified by a four-term fit to the PRFs from both the HILDA and box-diffusion advanced ocean models (which have very similar PRFs), thus capturing the ocean dynamics represented in these models (Joos et al., 1996). The ocean-atmosphere flux $f_{\mathrm{M}}$ is a nonlinear function of $\Theta$ and $c_{\mathrm{M} i}$ (as DIC) through phenomenological equations (Harman et al., 2011) that emulate full ocean carbonate chemistry (Lewis and Wallace, 1998).

Temperature: global temperature $\left(\Theta=\Theta_{q}+T\right)$ is taken to be the ocean mixed-layer temperature $\left(\Theta_{M}\right)$. The perturbation part $T_{\mathrm{M}}$ of $\Theta_{\mathrm{M}}$ is the sum of several components, so that $\Theta=\Theta_{q}+\sum T_{\mathrm{M} j}$. The components $T_{\mathrm{M} j}$ are governed by:

$\mathrm{d} T_{\mathrm{M} j} / \mathrm{d} t=b_{\mathrm{T} j} k_{\mathrm{T} j} \lambda_{q} \mathrm{RF}-k_{T j} T_{\mathrm{M} j}$,

where RF is the anthropogenic radiative forcing, $\lambda_{q}$ is the equilibrium climate sensitivity, and the weights $b_{\mathrm{T} j}$ and rates $k_{\mathrm{T} j}$ characterise the climate step response function (SRF) $1-\sum b_{\mathrm{T} j} \exp \left(-k_{\mathrm{T} j} t\right)$ (Raupach et al., 2011). A three-term climate step response function and associated $\lambda_{q}$ from the HadCM3 model (Li and Jarvis, 2009) are used here.

Radiative forcing: this is the sum of contributions from anthropogenic greenhouse gases $\left(\mathrm{CO}_{2}, \mathrm{CH}_{4}, \mathrm{~N}_{2} \mathrm{O}\right.$ and halocarbons, represented only by CFC-11 and CFC-12), together with aerosols:

$\mathrm{RF}=\mathrm{RF}_{\mathrm{CO}_{2}}+\mathrm{RF}_{\mathrm{CH}_{4}}+\ldots+\mathrm{RF}_{\text {Aero }}$.

Conventional expressions are used for radiative forcing as a function of gas concentration (IPCC, 2001, p. 358), specifically $\mathrm{RF}_{\mathrm{CO}_{2}}=5.35 \ln \left(\left[\mathrm{CO}_{2}\right] /\left[\mathrm{CO}_{2}\right]_{q}\right)$. The (negative) aerosol forcing is: 
Table B1. Parameters in SCCM (see Appendix B for sources) .

\begin{tabular}{|c|c|c|c|c|}
\hline Parameter & Eq. & Symbol & Units & Value \\
\hline Equilibrium terrestrial NPP & (B3) & $f_{\mathrm{NPP}}(q)$ & $\mathrm{PgC} \mathrm{yr}^{-1}$ & 40.0 \\
\hline NPP multiplier & (B3) & $m_{\mathrm{NPP}}$ & - & 1.5 \\
\hline NPP slope parameter & (B3) & $c_{\mathrm{NPP}}$ & $\mathrm{PgC}$ & 687 \\
\hline NPP power parameter & (B3) & $p$ & - & 2.5 \\
\hline Equilibrium respiration rate & & $k_{\mathrm{L} 1(q)}$ & $\mathrm{yr}^{-1}$ & $1 / 2.5$ \\
\hline Equilibrium respiration rate & & $k_{\mathrm{L} 2(q)}$ & $\mathrm{yr}^{-1}$ & $1 / 250$ \\
\hline$q_{10}$ for respiration & & $q_{10}$ & - & 2.0 \\
\hline NPP partition fraction & (B2) & $a_{\mathrm{L} 1}$ & - & 0.5 \\
\hline NPP partition fraction & (B2) & $a_{\mathrm{L} 2}$ & - & $1-a_{\mathrm{L} 1}$ \\
\hline Air-ocean gas exchange rate & & $k_{\mathrm{Gas}}$ & $\mathrm{yr}^{-1}$ & $1 / 8.76$ \\
\hline Preindustrial land C stores & & $C_{\mathrm{L} i}$ & $\mathrm{PgC}$ & $\frac{a_{\mathrm{L} i} f_{\mathrm{NPP}(q)}}{k_{\mathrm{L} i}(q)}$ \\
\hline Preindustrial DIC & & $\mathrm{DIC}_{q}$ & $\mathrm{molC} \mathrm{m}^{-3}$ & 2.089 \\
\hline Ocean $\mathrm{CO}_{2}$ PRF: weights & (B5) & $a_{\mathrm{C} i}$ & - & $\begin{array}{l}0.512934,0.320278, \\
0.142183,0.0246045\end{array}$ \\
\hline Ocean $\mathrm{CO}_{2}$ PRF: rates & (B5) & $k_{\mathrm{C} i}$ & $\mathrm{yr}^{-1}$ & $\begin{array}{l}5.22893,0.356532 \\
0.0194692,0.0\end{array}$ \\
\hline Decay rate for $\mathrm{CH}_{4}$ & (B10) & $k_{\mathrm{CH} 4}$ & $\mathrm{yr}^{-1}$ & $8.2^{-1}\left(\left[\mathrm{CH}_{4}\right] /\left[\mathrm{CH}_{4}\right]_{0}\right)^{-0.12}$ \\
\hline Decay rate for $\mathrm{N}_{2} \mathrm{O}$ & (B10) & $k_{\mathrm{N} 2 \mathrm{O}}$ & $\mathrm{yr}^{-1}$ & $1 / 114$ \\
\hline Decay rate for CFC-11 & (B10) & $k_{\mathrm{CFC} 11}$ & $\mathrm{yr}^{-1}$ & $1 / 45$ \\
\hline Decay rate for CFC-12 & (B10) & $k_{\mathrm{CFC} 12}$ & $\mathrm{yr}^{-1}$ & $1 / 100$ \\
\hline Preindustrial $\left[\mathrm{CO}_{2}\right]$ & & {$\left[\mathrm{CO}_{2}\right]_{q}$} & ppm & 280 \\
\hline Preindustrial $\left[\mathrm{CH}_{4}\right]$ & (B10) & {$\left[\mathrm{CH}_{4}\right]_{q}$} & $\mathrm{ppb}$ & 700 \\
\hline Preindustrial $\left[\mathrm{N}_{2} \mathrm{O}\right]$ & (B10) & {$\left[\mathrm{N}_{2} \mathrm{O}\right]_{q}$} & $\mathrm{ppb}$ & 270 \\
\hline Preindustrial $[\mathrm{CFC}]$ & (B10) & {$[\mathrm{CFC}]_{q}$} & ppb & 0 \\
\hline Preindustrial temperature & & $\Theta_{q}$ & $\operatorname{deg} C$ & 15 \\
\hline Coefficient for aerosol RF & (B9) & $c_{\text {Aero }}$ & $\mathrm{RF} /\left[f_{\mathrm{FFoss}}\right]$ & Eq. (B9) \\
\hline Climate SRF: weights & (B7) & $b_{\mathrm{T} j}$ & - & $0.434,0.175,0.391$ \\
\hline Climate SRF: rates & (B7) & $k_{\mathrm{T} j}$ & $\mathrm{yr}^{-1}$ & $4.51^{-1}, 140.4^{-1}, 1476^{-1}$ \\
\hline Equilibrium climate sensitivity & (B7) & $\lambda_{q}$ & $\mathrm{KW}^{-1} \mathrm{~m}^{2}$ & 1.235 \\
\hline
\end{tabular}

$\mathrm{RF}_{\text {Aero }}=c_{\text {Aero }}(t) f_{\text {Foss }}(t)$

$c_{\text {Aero }}(t)=-0.12(1-\tanh ((t-2000) / 100))$.

This assumes proportional relationships between aerosol radiative forcing, aerosol concentrations, aerosol emissions (taking the aerosol turnover rate to be rapid) and fossil fuel emissions, for instance though sulphate emissions associated with coal combustion. To account for technological improvements, the proportionality coefficient $c_{\text {Aero }}$ has a sigmoidal time dependence. Equation (B8) yields $\mathrm{RF}=+1.6 \mathrm{~W} \mathrm{~m}^{-2}$ in 2005 (IPCC, 2007).

Non- $\mathrm{CO}_{2}$ greenhouse gases: for $\mathrm{CH}_{4}, \mathrm{~N}_{2} \mathrm{O}$ and $\mathrm{CFCs}$, total concentrations $[\mathrm{X}]$ are determined by the mass balances

$\frac{\mathrm{d}[\mathrm{X}]}{\mathrm{d} t}=r_{\mathrm{X}}^{-1}\left(f_{\mathrm{X}(\mathrm{Nat})}+f_{\mathrm{X}(\mathrm{Anth})}(t)\right)-k_{\mathrm{X}}[\mathrm{X}]$,

with mass-concentration ratios $r_{\mathrm{X}}$ (with units $\mathrm{TgCH}_{4} \mathrm{ppb}^{-1}$ and likewise for other gases), fluxes $f_{\mathrm{X}}$ (separating natural and anthropogenic components) and atmospheric decay rates $k_{\mathrm{X}}$. The decay rates for $\mathrm{N}_{2} \mathrm{O}$ and CFCs are constant, while that for $\mathrm{CH}_{4}$ is a weak function of concentration (Raupach et al., 2011) to account for the decrease in $\mathrm{CH}_{4}$ decay rate from preindustrial to present times (Prinn, 2004). Natural emission fluxes $f_{\mathrm{X}(\mathrm{Nat})}$ are taken as time-independent and set to match preindustrial concentrations in the assumed preindustrial equilibrium state.

Forcing: the forcing fluxes are $\mathrm{CO}_{2}$ emissions from fossil fuels and other industrial processes $\left(f_{\mathrm{Foss}}\right), \mathrm{CO}_{2}$ emissions from net land use change $\left(f_{\mathrm{LUC}}\right)$, and anthropogenic emission fluxes of $\mathrm{CH}_{4}, \mathrm{~N}_{2} \mathrm{O}$ and CFCs. For the past, all forcing fluxes are prescribed from data: $f_{\text {Foss }}$ from the Carbon Dioxide Information and Analysis Center (CDIAC, 2012); $f_{\text {LUC }}$ from R. A. Houghton (GFRA, 2012); recent preliminary estimates of $f_{\mathrm{Foss}}$ and $f_{\mathrm{Foss}}$ from GCP (2011); and emissions of $f_{\mathrm{X} \text { (Anth) }}$ for $\mathrm{CH}_{4}, \mathrm{~N}_{2} \mathrm{O}$ and CFCs from the RCP database (Meinshausen et al., 2011; IIASA, 2012). The volcanic aerosol index (Eq. B3) is from Ammann et al. (2003), assuming no volcanic eruptions since 2000. 
For the future, forcing fluxes are prescribed with scenarios such as SRES (Nakicenovic et al., 2000), RCP (Meinshausen et al., 2011; IIASA, 2012) or analytic forms. In Figs. 6 and 7, future $f_{\text {Foss }}(t)$ is prescribed with a "smooth capped" analytic emissions trajectory that merges an initial exponentialgrowth phase (with growth rate $r$ ) with a mitigation phase in which emissions ultimately decrease exponentially at a mitigation rate $m$, set to yield specified all-time cumulative emissions $Q_{\mathrm{E}}(\infty)$ (Raupach et al., 2011). Other future analytic emissions trajectories used in Figs. 6 and 7 are: $f_{\mathrm{LUC}}(t)$ decreases linearly from the latest observed value to zero at $t=2100 ; f_{\mathrm{CH}_{4}}(t)$ and $f_{\mathrm{N}_{2} \mathrm{O}}(t)$ are held constant at latest observed values; and $\mathrm{CFC}$ emissions decline exponentially at $3 \%^{-1}$ (CFC-11) and $6 \%^{-1}$ (CFC-12), consistent with RCP scenarios. No volcanic eruptions are postulated in future scenarios.

Parameters: model parameters, given in Table B1, were set to produce best available agreement with observations from 1850 to 2011 for $\left[\mathrm{CO}_{2}\right], \mathrm{AF}, k_{\mathrm{S}}$, non- $\mathrm{CO}_{2}$ gas concentrations $\left(\left[\mathrm{CH}_{4}\right],\left[\mathrm{N}_{2} \mathrm{O}\right]\right.$, [CFC-11], [CFC-12]), and perturbation temperature $T$. Formal parameter estimation was not used.

Linearisation: the linearised version of SCCM in Figs. 8 and 9 was constructed by linearising the following nonlinear relationships: (1) the relationship between terrestrial NPP and atmospheric $\left[\mathrm{CO}_{2}\right]$ (Eq. B3); (2) the relationship between ocean mixed-layer DIC and $\left[\mathrm{CO}_{2}\right]$ (Lewis and Wallace, 1998; Harman et al., 2011); and (3) the relationship between radiative forcing and $\left[\mathrm{CO}_{2}\right]$. In each case, the nonlinear relationship was replaced with a linearised version giving the same result at $\left[\mathrm{CO}_{2}\right]$ values of $280 \mathrm{ppm}$ (preindustrial) and $400 \mathrm{ppm}$.

Changes from earlier versions: relative to earlier SCCM versions (Raupach et al., 2011; Harman et al., 2011), the version used here includes several changes: (1) a new form for terrestrial NPP (Eq. B3); (2) inclusion of a dependence of terrestrial NPP on volcanic eruptions; (3) emulation of full ocean carbonate chemistry (Lewis and Wallace, 1998; Harman et al., 2011); (4) time dependence of cAero (Eq. B9); (5) improved data on past emissions of non- $\mathrm{CO}_{2}$ gases (IIASA, 2012); and (6) minor adjustments to parameters because of these changes.

\section{Appendix C}

\section{Data sources}

$\mathrm{CO}_{2}$ emissions from fossil fuels ( $\left.f_{\text {Foss }}\right)$ are from the Carbon Dioxide Information and Analysis Center (CDIAC, 2012). Net $\mathrm{CO}_{2}$ emissions from land use change $\left(f_{\text {LUC }}\right)$ are from R. A. Houghton (GFRA, 2012). Recent preliminary emissions estimates and data collation are by the Global Carbon Project (GCP, 2011). Atmospheric $\mathrm{CO}_{2}$ concentration data prior to 1959 from the Law Dome ice core (Etheridge et al., 1996); for 1959 to 1980 from averaged in situ measurements at Mauna Loa (Hawaii) and the South Pole (Scripps $\mathrm{CO}_{2}$ Program, 2012); and for 1980 to 2011 from globally averaged in situ data (NOAA-ESRL, 2012). Temperature data are from the Climatic Research Unit (CRU), University of East Anglia, UK (CRU, 2012), the Goddard Institute for Space Studies, USA (NASA-GISS, 2012), and the National Climatic Data Center, USA (NOAA-NCDC, 2012).

Acknowledgements. I thank Pep Canadell, Philippe Ciais, Ian Enting, Manuel Gloor, Corinne Le Quéré, Jorge Sarmiento, and especially Ian Harman and Cathy Trudinger, for discussions that have helped to motivate and advance the work described here. I am indebted to three referees (Andrew Jarvis, Kirsten Zickfeld and an anonymous referee) for detailed and constructive comments. This work was supported by the Australian Climate Change Research Program (ACCSP) of the Department of Climate Change and Energy Efficiency, Australian Government. The work is a contribution to ACCSP and the Global Carbon Project (http://www.globalcarbonproject.org/).

Edited by: H. Held

\section{References}

Allen, M. R., Frame, D. J., Huntingford, C., Jones, C. D., Lowe, J. A., Meinshausen, M., and Meinshausen, N.: Warming caused by cumulative carbon emissions: towards the trillionth tonne, Nature, 458, 1163-1166, 2009.

Ammann, C. M., Meehl, G. A., Washington, W. M., and Zender, C. S.: A monthly and latitudinally varying volcanic forcing dataset in simulations of 20th century climate, Geophys. Res. Lett., 30, 1657, doi:10.1029/2003GL016875, 2003.

Bacastow, R. B. and Keeling, C. D.: Models to predict future atmospheric $\mathrm{CO}_{2}$ concentrations, in: Workshop on the Global Effects of Carbon Dioxide from Fossil Fuels, edited by: Elliott, W. P. and Machta, L., United States Department of Energy, Washington, D.C., 72-90, 1979.

Canadell, J. G., Le Quéré, C., Raupach, M. R., Field, C. B., Buitenhuis, E. T., Ciais, P., Conway, T. J., Gillett, N. P., Houghton, R. A., and Marland, G.: Contributions to accelerating atmospheric $\mathrm{CO}_{2}$ growth from economic activity, carbon intensity, and efficiency of natural sinks, P. Natl. Acad. Sci. USA, 104, 1886618870, 2007.

CDIAC: Fossil-fuel $\mathrm{CO}_{2}$ emissions, Carbon Dioxide Information and Analysis Center, US Department of Energy, available at: http://cdiac.ornl.gov/trends/emis/meth_reg.html, last access: 23 July, 2012.

CRU: Global temperature data, Climatic Research Unit, University of East Anglia, available at: http://www.cru.uea.ac.uk/cru/data/ temperature/, last access: 13 June, 2012.

Enting, I. G.: Laplace transform analysis of the carbon cycle, Environ. Model. Softw., 22, 1488-1497, 2007.

Etheridge, D. M., Steele, L. P., Langenfelds, R. L., Francey, R. J., Barnola, J. M., and Morgan, V. I.: Natural and anthropogenic changes in atmospheric $\mathrm{CO}_{2}$ over the last 1000 years from air in Antarctic ice and firn, J. Geophys. Res.-Atmos., 101, 41154128, 1996. 
Francey, R. J., Trudinger, C. M., van der Schoot, M., Krummel, P. B., Steele, L. P., and Langenfelds, R. L.: Differences between trends in atmospheric $\mathrm{CO}_{2}$ and the reported trends in anthropogenic $\mathrm{CO}_{2}$ emissions, Tellus B, 62, 316-328, 2010.

Friedlingstein, P., Cox, P., Betts, R., Bopp, L., von Bloh, W., Brovkin, V., Cadule, P., Doney, S., Eby, M., Fung, I., Bala, G., John, J., Jones, C., Joos, F., Kato, T., Kawamiya, M., Knorr, W., Lindsay, K., Matthews, H. D., Raddatz, T., Rayner, P., Reick, C., Roeckner, E., Schnitzler, K. G., Schnur, R., Strassmann, K., Weaver, A. J., Yoshikawa, C., and Zeng, N.: Climate-carbon cycle feedback analysis: Results from the C4MIP model intercomparison, J. Climate, 19, 3337-3353, 2006.

Frölicher, T. L., Joos, F., Raible, C. C., and Sarmiento, J. L.: Atmospheric $\mathrm{CO}_{2}$ response to volcanic eruptions: the role of ENSO, season, and variability, Global Biogeochem. Cy., in press, 2012.

GCP: Global carbon budget, Global Carbon Project, http:// www.globalcarbonproject.org/carbonbudget/index.htm, last access: 15 February, 2012.

Gershenfeld, N. A.: The Nature of Mathematical Modeling, Cambridge University Press, Cambridge, p. 344, 1999.

GFRA: Global Forest Resources Assessment 2010, Food and Agriculture Organization, available at: http://www.fao.org/forestry/ fra/fra2010/en/, last access: 11 June, 2012.

Glendinning, P.: Stability, Instability and Chaos: an Introduction to the Theory of Nonlinear Differential Equations, Cambridge University Press, Cambridge, 1-388, 1994.

Gloor, M., Sarmiento, J. L., and Gruber, N.: What can be learned about carbon cycle climate feedbacks from the $\mathrm{CO}_{2}$ airborne fraction?, Atmos. Chem. Phys., 10, 7739-7751, doi:10.5194/acp10-7739-2010, 2010.

Hansen, J. E., Sato, M., Kharecha, P., Beerling, D. J., MassonDelmotte, V., Pagani, M., Raymo, M., Royer, D., and Zachos, J.: Target Atmospheric $\mathrm{CO}_{2}$ : Where Should Humanity Aim?, Open Atmos. Sci. J., 2, 217-231, 2008.

Harman, I. N., Trudinger, C. M., and Raupach, M. R.: SCCM - the Simple Carbon-Climate Model: technical documentation, CAWCR Technical Report no. 47, Centre for Australian Weather and Climate Research, Bureau of Meteorology and CSIRO, Melbourne, Australia, 2011.

Hasselmann, K., Hasselmann, S., Giering, R., Ocana, V., and VonStorch, H.: Sensitivity study of optimal $\mathrm{CO}_{2}$ emission paths using a simplified structural integrated assessment model (SIAM), Climatic Change, 37, 345-386, 1997.

Hooss, G., Voss, R., Hasselmann, K., Maier-Reimer, E., and Joos, F.: A nonlinear impulse response model of the coupled carbon cycle-climate system (NICCS), Clim. Dynam., 18, 189-202, 2001.

Huntingford, C. and Cox, P. M.: An analogue model to derive additional climate change scenarios from existing GCM simulations, Clim. Dynam., 16, 575-586, 2000.

IIASA: RCP Database, version 2.0, International Institute for Applied Systems Analysis, Laxenburg, Austria, 17 June, 2012.

IPCC: Climate Change 2001: The Scientific Basis, Contribution of Working Group I to the Third Assessment Report of the Intergovernmental Panel on Climate Change, edited by: Houghton, J. T., Ding, Y., Griggs, D. J., Noguer, M., van der Linden, P. J., Dai, X., Maskell, K., and Johnson, C. A., Cambridge University Press, Cambridge, UK and New York, 2001.
IPCC: Climate Change 2007: The Physical Science Basis, Contribution of Working Group I to the Fourth Assessment Report of the Intergovernmental Panel on Climate Change, Cambridge University Press, Cambridge, UK and New York, NY, USA, p. 996, 2007.

Jarvis, A. J., Leedal, D. T., and Hewitt, C. N.: Climate-society feedbacks and the avoidance of dangerous climate change, Nature Clim. Change, 2, 668-671, 2012.

Jones, C. D. and Cox, P. M.: Modeling the volcanic signal in the atmospheric $\mathrm{CO}_{2}$ record, Global Biogeochem. Cy., 15, 453-465, 2001.

Joos, F., Bruno, M., Fink, R., Siegenthaler, U., Stocker, T. F., and Le Quéré, C.: An efficient and accurate representation of complex oceanic and biospheric models of anthropogenic carbon uptake, Tellus B, 48, 397-417, 1996.

Joos, F., Prentice, I. C., Sitch, S., Meyer, R., Hooss, G., Plattner, G. K., Gerber, S., and Hasselmann, K.: Global warming feedbacks on terrestrial carbon uptake under the Intergovernmental Panel on Climate Change (IPCC) emission scenarios, Global Biogeochem. Cy., 15, 891-907, 2001.

Joos, F., Roth, R., Fuglestvedt, J. S., Peters, G. P., Enting, I. G., von Bloh, W., Brovkin, V., Burke, E. J., Eby, M., Edwards, N. R., Friedrich, T., Frölicher, T. L., Halloran, P. R., Holden, P. B., Jones, C., Kleinen, T., Mackenzie, F., Matsumoto, K., Meinshausen, M., Plattner, G.-K., Reisinger, A., Segschneider, J., Shaffer, G., Steinacher, M., Strassmann, K., Tanaka, K., Timmermann, A., and Weaver, A. J.: Carbon dioxide and climate impulse response functions for the computation of greenhouse gas metrics: a multi-model analysis, Atmos. Chem. Phys. Discuss., 12, 19799-19869, doi:10.5194/acpd-12-19799-2012, 2012.

Keeling, C. D. and Revelle, R.: Effects of El-Nino Southern Oscillation on the Atmospheric Content of Carbon-Dioxide, Meteoritics, 20, 437-450, 1985.

Le Quéré, C., Raupach, M. R., Canadell, J. G., Marland, G., Bopp, L., Ciais, P., Conway, T. J., Doney, S. C., Feely, R. A., Foster, P., Friedlingstein, P., Gurney, K. R., Houghton, R. A., House, J. I., Huntingford, C., Levy, P. E., Lomas, M. R., Majkut, J., Metzl, N., Ometto, J., Peters, G. P., Prentice, I. C., Randerson, J. T., Running, S. W., Sarmiento, J. L., Schuster, U., Sitch, S., Takahashi, T., Viovy, N., van der Werf, G. R., and Woodward, F. I.: Trends in the sources and sinks of carbon dioxide, Nat. Geosci., 2, 831836, doi:10.1038/NGEO689, 2009.

Lewis, E. and Wallace, D. J. Program developed for $\mathrm{CO}_{2}$ system calculations, ORNL-CDIAC-105, Carbon Dioxide Information Analysis Center, Oak Ridge National Laboratory, Oak Ridge, Tennessee, 38, 1998.

Li, S. and Jarvis, A.: Long run surface temperature dynamics of an A-OGCM: the HadCM3 $4 \times \mathrm{CO}_{2}$ forcing experiment revisited, Clim. Dynam., 33, 817-825, 2009.

Li, S., Jarvis, A. J., and Leedal, D. T.: Are response function representations of the global carbon cycle ever interpretable?, Tellus B, 61, 361-371, 2009.

MacDougall, A. H., Avis, C. A., and Weaver, A. J.: Significant contribution to climate warming from the permafrost carbon feedback, Nat. Geosci., 5, 719-721, 2012.

Matthews, H. D., Gillett, N. P., Stott, P. A., and Zickfeld, K.: The proportionality of global warming to cumulative carbon emissions, Nature, 459, 829-833, 2009. 
Meinshausen, M., Meinshausen, N., Hare, W., Raper, S. C. B., Frieler, K., Knutti, R., Frame, D. J., and Allen, M. R.: Greenhouse gas emission targets for limiting global warming to $2 \mathrm{degC}$, Nature, 458, 1158-1162, 2009.

Meinshausen, M., Smith, S. J., Calvin, K., Daniel, J. S., Kainuma, M. L. T., Lamarque, J. F., Matsumoto, K., Montzka, S. A., Raper, S. C. B., Riahi, K., Thomson, A., Velders, G. J. M., and van Vuuren, D. P. P.: The RCP greenhouse gas concentrations and their extensions from 1765 to 2300, Climatic Change, 109, 213-241, 2011.

Moss, R. H., Edmonds, J. A., Hibbard, K. A., Manning, M. R., Rose, S. K., van Vuuren, D. P., Carter, T. R., Emori, S., Kainuma, M., Kram, T., Meehl, G. A., Mitchell, J. F. B., Nakicenovic, N., Riahi, K., Smith, S. J., Stouffer, R. J., Thomson, A. M., Weyant, J. P., and Wilbanks, T. J.: The next generation of scenarios for climate change research and assessment, Nature, 463, 747-756, 2010.

Nakicenovic, N., Alcamo, J., Davis, G., de Vries, B., Fenhann, J., Gaffin, S., Gregory, K., Grubler, A., Jung, T. Y., Kram, T., La Rovere, E. L., Michaelis, L., Mori, S., Morita, T., Pepper, W., Pitcher, H., Price, L., Raihi, K., Roehrl, A., Rogner, H.-H., Sankovski, A., Schlesinger, M., Shukla, P., Smith, S., Swart, R., van Rooijen, S., Victor, N., and Dadi, Z.: IPCC Special Report on Emissions Scenarios, Cambridge University Press, Cambridge, UK and New York, p. 599, 2000.

NASA-GISS: GISS surface temperature analysis (GISTEMP), National Aeronautics and Space Administration, USA, available at: http://data.giss.nasa.gov/gistemp/, last access: 13 June, 2012.

NOAA-ESRL: Trends in Atmospheric Carbon Dioxide, Earth System Research Laboratory, National Oceanic and Atmospheric Admisinstration, available at: http://www.esrl.noaa.gov/ gmd/ccgg/trends/, last access: 13 June, 2012.

NOAA-NCDC: Global surface temperature anomalies, National Climatic Data Center, National Oceanic and Atmospheric Administration, USA, available at: http://www.ncdc.noaa.gov/ cmb-faq/anomalies.php, last access: 13 June, 2012.

Oeschger, H., Siegenthaler, U., Schotterer, U., and Gugelmann, A.: Box Diffusion-Model to Study Carbon-Dioxide Exchange in Nature, Tellus B, 27, 168-192, 1975.

Petschel-Held, G., Schellnhuber, H. J., Bruckner, T., Toth, F. L., and Hasselmann, K.: The tolerable windows approach: Theoretical and methodological foundations, Climatic Change, 41, 303-331, 1999.

Prinn, R. G.: Non- $\mathrm{CO}_{2}$ greenhouse gases, in: The Global Carbon Cycle: Integrating Humans, Climate, and the Natural World, edited by: Field, C. B. and Raupach, M. R., Island Press, Washington, 205-216, 2004.

Raper, S. C. B., Gregory, J. M., and Osborn, T. J.: Use of an upwelling-diffusion energy balance climate model to simulate and diagnose A/OGCM results, Clim. Dynam., 17, 601-613, 2001.
Raupach, M. R., Canadell, J. G., and Le Quéré, C.: Anthropogenic and biophysical contributions to increasing atmospheric $\mathrm{CO}_{2}$ growth rate and airborne fraction, Biogeosciences, 5, 1601-1613, doi:10.5194/bg-5-1601-2008, 2008.

Raupach, M. R., Canadell, J. G., Ciais, P., Friedlingstein, P., Rayner, P. J., and Trudinger, C. M.: The relationship between peak warming and cumulative $\mathrm{CO}_{2}$ emissions, and its use to quantify vulnerabilities in the carbon-climate-human system, Tellus B, 63, 145-164, 2011.

Sarmiento, J. L., Gloor, M., Gruber, N., Beaulieu, C., Jacobson, A. R., Mikaloff Fletcher, S. E., Pacala, S., and Rodgers, K.: Trends and regional distributions of land and ocean carbon sinks, Biogeosciences, 7, 2351-2367, doi:10.5194/bg-7-2351-2010, 2010.

Schuur, E. A. G., Bockheim, J., Canadell, J. G., Euskirchen, E., Field, C. B., Goryachkin, S. V., Hagemann, S., Kuhry, P., Lafleur, P., Lee, H., Mazhitova, G., Nelson, F. E., Rinke, A., Romanovsky, V. E., Shiklomanov, N., Tarnocai, C., Venevsky, S., Vogel, J. G., and Zimov, S. A.: Vulnerability of permafrost carbon to climate change: implications for the global carbon cycle, BioScience, 58, 701-714, 2008.

Scripps $\mathrm{CO}_{2}$ Program: Atmospheric $\mathrm{CO}_{2}$ data, Scripps Institution of Oceanography, available at: http://scrippsco2.ucsd.edu/data/ data.html, last access: 13 June, 2012.

Sitch, S., Huntingford, C., Gedney, N., Levy, P. E., Lomas, M., Piao, S. L., Betts, R., Ciais, P., Cox, P., Friedlingstein, P., Jones, C. D., Prentice, I. C., and Woodward, F. I.: Evaluation of the terrestrial carbon cycle, future plant geography and climate-carbon cycle feedbacks using five Dynamic Global Vegetation Models (DGVMs), Global Change Biol., 14, 2015-2039, 2008.

Strassmann, K. M., Plattner, G. K., and Joos, F.: $\mathrm{CO}_{2}$ and non- $\mathrm{CO}_{2}$ radiative forcings in climate projections for twenty-first century mitigation scenarios, Clim. Dynam., 33, 737-749, 2009.

Tarnocai, C., Canadell, J. G., Schuur, E. A. G., Kuhry, P., Mazhitova, G., and Zimov, S. A.: Soil organic carbon pools in the northern circumpolar permafrost region, Global Biogeochem. Cy., 23, GB2023, doi:10.1029/2008GB003327, 2009.

Trudinger, C. M., Enting, I. G., Rayner, P. J., and Francey, R. J.: Kalman filter analysis of ice core data -2 . Double deconvolution of $\mathrm{CO}_{2}$ and delta $\mathrm{C}^{13}$ measurements, J. Geophys. Res.-Atmos., 107, 4422, doi:10.1029/2001JD001112, 2002.

van Vuuren, D. P., Edmonds, J., Kainuma, M., Riahi, K., Thomson, A., Hibbard, K., Hurtt, G. C., Kram, T., Krey, V., Lamarque, J. F., Masui, T., Meinshausen, M., Nakicenovic, N., Smith, S. J., and Rose, S. K.: The representative concentration pathways: an overview, Climatic Change, 109, 5-31, 2011.

Zickfeld, K., Eby, M., Matthews, H. D., and Weaver, A. J.: Setting cumulative emissions targets to reduce the risk of dangerous climate change, P. Natl. Acad. Sci. USA, 106, 16129-16134, 2009. 